1 Experimental flow field comparison for a series of scale model oscillating water column

2 wave energy converters

3 Alan N. Fleming ${ }^{a}$, Gregor J. Macfarlane ${ }^{a}$

4 a. Australian Maritime College, University of Tasmania, Launceston, Tasmania, Australia

\title{
5 Abstract
}

6 This paper presents an analysis of 2D PIV model test experiments performed on a series of forward-

7 facing bent-duct type of oscillating water column (OWC) models with varied underwater geometry.

8 Experiments of this complexity involving particle imaging velocimetry (PIV) to compare performance

9 difference between differing geometry is the first of its type. The intent of the experiments was to

10 investigate conversion losses and device performance by modifying the underwater geometry based on previous work by the authors. Four models were tested in total; the base model and three variations that had additional segments to afford different chamber length and lower/upper lip angles (10, 20 and 30 degrees). Dynamic similarity was assumed to be maintained between models by using a constant lower lip depth and a constant ratio of chamber length to projected underwater cross-sectional area.

Performance comparisons were undertaken using phase-averaged wave probe, pressure transducer and PIV data. Additional qualitative analysis of velocity fields was performed using temporal averaging. In most test cases the new geometry with a 10 degree lip angle had marginally superior performance in terms of capture width and total power production. However, due to a number of issues, including the difference in damping factor between models; the difference in chamber length; and the void behind the upper lip on some models, it was not possible to definitively conclude that the 10 degree model was the best performer, but rather, the range of all new geometries presented have the potential for significant performance gains over the base geometry with additional modifications.

\section{Introduction}

Ocean wave energy is an emerging renewable energy technology, with many concepts at the precommercial stage. As device technology becomes more established there is the natural move towards optimising device conversion performance. In the case of the oscillating water column (OWC), the concept is well proven, however device geometry (in particular underwater geometry) is still not optimal and may require site-specific customisation (eg see [1,2]). Experimental analysis is an important tool as the development of wave energy converters [3] and will be the focus of this paper.

It is well known that flow past sharp edges will produce disturbed flow and consequently loss of energy, or more precisely - conversion of energy to turbulence and vorticity [4-6]. This is of particular importance for oscillating flows, such as those experienced by many wave energy converters, and this results in energy losses as the turbulence/vorticity is no longer available for extraction $[7,8]$. For OWCs, rounding of the front lip has been used to minimise energy losses (see for example [1,9]). In terms of improving device efficiency, other studies have considered various modifications to geometry, including; chamber length, width of the front lip, angle of the OWC floor and entrance shape. For example, Tseng et al. [10] propose flared side walls and a projecting curved upper-lip for the entrance shape of a shoreline multi-OWC. McCormick and Altera [11] compared a circular to square water-plane (using a totally damped system) and found that the square water-plane radiated less wave energy compared to the round. Sarmento [1] reported on location specific optimization of an onshore OWC in $7 \mathrm{~m}$ of water between rocky walls in a natural harbour in the 
43 Azores archipelago to give optimal site specific model dimensions (chamber length and front lip

44 submergence).

45 Koola [12] found that the multi-OWC (a normal OWC with projecting side walls) had best performance with projecting side walls of length equal to the chamber length. Hong et al. [13] performed 2D parametric experiments on the shape parameters including depth of lip, chamber length and damping factor and observed the proportional relationship between air chamber length and natural frequency (a longer chamber has a correspondingly lower resonant frequency). Dizadji and Sajadian [14] performed experiments investigating the effect of modifying the angle of both the front and back walls independently for a two-dimensional model of an OWC for a single polychromatic wave condition. They found that a vertical back wall was more productive than a sloped back wall. Rezanejad et al. [15] conducted a 2D numerical study in which they introduced a step beneath the OWC to produce an additional resonant frequency corresponding to "the well-known quarter wave length resonance in a half open organ pipe". Results presented show that extending the step from the back wall of the OWC to a distance equal to the water depth past the front wall improves the efficiency bandwidth, particularly for lower frequency waves.

Importantly, in most cases mentioned above, the interaction of the flow field with the OWC is treated as a 'black box' with no opportunity to assess the impact the OWC geometry has directly on the flow field. Two-dimensional particle imaging velocimetry (2D PIV) is an optical based experimental technique for obtaining quantitative spatial flow field information in a plane. Velocity vector representation of velocity fields provides a powerful visualisation tool which gives the experimenter valuable insight into complex fluid structure interaction. PIV is particularly useful for flow visualisation in reversing/oscillating flow where steady flow visualisation techniques cannot be used.

Obtaining quality flow field information inside and around the OWC provides a wealth of information about the devices operation and can be used both qualitatively to visualise the flow to identify inefficiencies in the design of the underwater geometry and to quantify various flow properties $[7,16]$. The resultant flow field data is also ideal for validating computational fluid dynamics (CFD).

This paper reports on the novel application of PIV to perform a parametric analysis of a forward-

facing bent-duct OWC in scale model experiments using four separate models. The models are detailed in the following section but the major difference between them is the chamber length and angle of the upper and lower lips. By acquiring both 'conventional' measurements to assess the power output of the devices and novel measurements of the flow field, the impact of changing the lip angle is determined and discussed. Suggestions for future OWC design are proposed.

\section{$75 \quad 2$ Methodology}

Experiments were conducted in the Australian Maritime College (AMC) towing tank. This facility is $100 \mathrm{~m}$ long, $3.5 \mathrm{~m}$ wide and $1.5 \mathrm{~m}$ deep. A hydraulically driven paddle type wave maker is located at one end of the tank and a passive sloped beach is located at the other end. Experimental layout is shown in Figure 1 with each model in turn positioned at the centre of the tank crosswise and approximately $60 \mathrm{~m}$ from the wave paddle, adjacent to a window in the side of the tank; the opening of the OWC model faced the incoming waves. Underwater laser sheet optics were positioned aft of the model directing the light sheet through the centreline plane of the model, which was fabricated of $6 \mathrm{~mm}$ thick clear acrylic and fixed rigidly in position using a frame connected to the stationary towing tank carriage. 


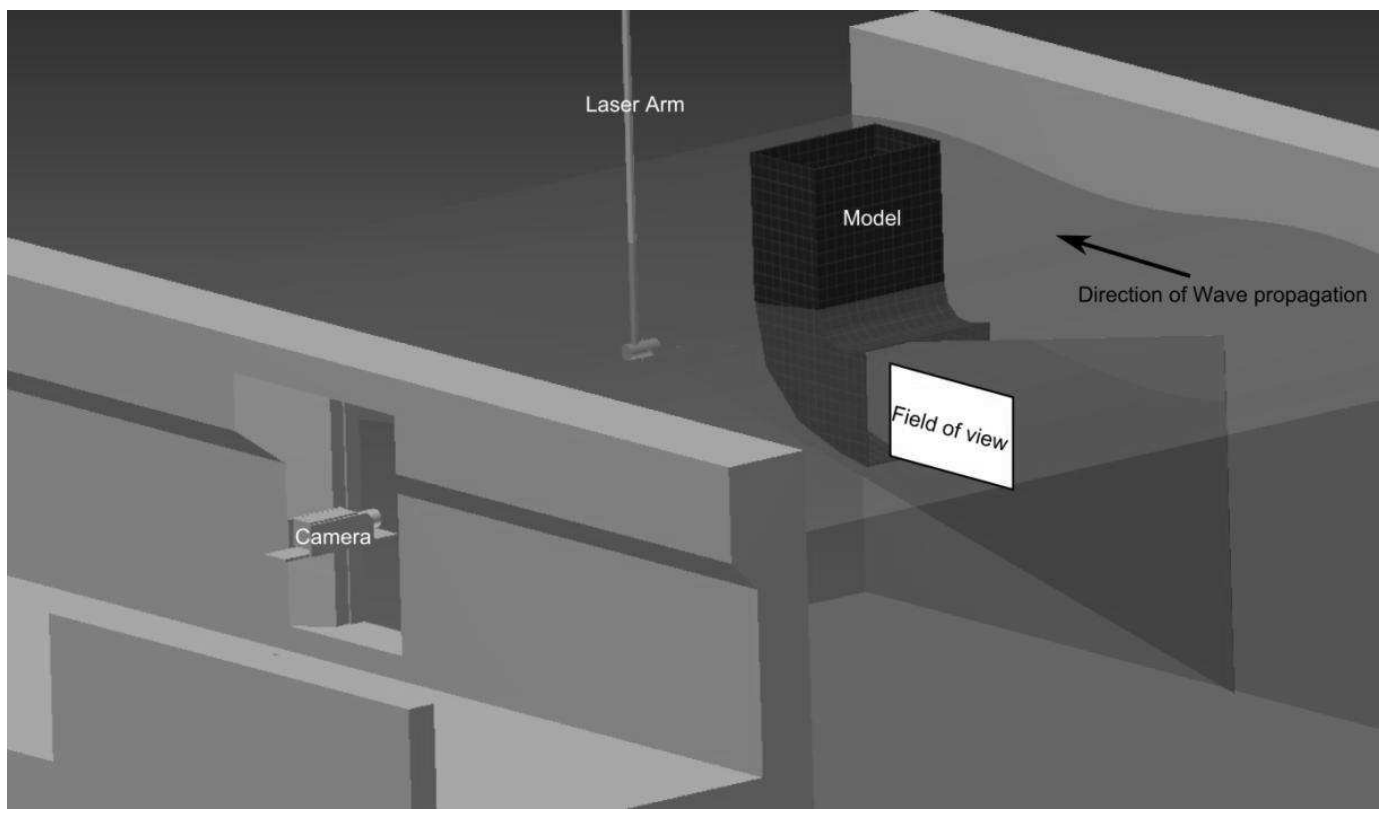

Figure 1: Experimental setup shown in cut-out of AMC towing tank, pulsed laser light sheet is shown extending from the laser arm (laser not shown)

\subsection{Geometry}

In previous studies by the authors to investigate the flow field inside the base model using PIV, it was found that significant energy losses were associated with underwater geometry that produced vortices $[7,17]$. In particular significant vortices were present at the upper and lower lips, and at the transition between the upper-lip and the chamber front wall. A nominal scale of 1:40 can be assumed.

New geometry was developed with the intention of reducing the production of vortices inside the device caused by translation of flow around sharp corners. This was achieved by using a parameter type basis using three equal length segments to transition between both; the aft chamber wall and lower lip, and the front chamber wall and upper lip. For the lower lip segments; the nodes of the segments lie on splines tangential to the aft chamber wall and the lower lip, while the nodes of the upper lip segments lie on an arc tangential to the forward chamber wall and the upper lip. Differing models were developed for the three different lip angles of 10, 20 and 30 degrees. The depth of the lower lip for each model was fixed at $-442 \mathrm{~mm}$ and the $x$ location of the upper and lower lips were set equal. The final shape of the model was then obtained by using an optimisation algorithm to adjust the $x$ location of the upper and lower lips such that the ratio of the length between the forward and aft chamber walls to area bound by the geometry below the still water level $(<z=0)$ was a constant value. This was intended to maintain a constant hydrostatic spring-to-mass ratio.

Although these physical experiments provide a valuable data set, the small scale of the model devices result in flow conditions in which transitional effects and turbulence development will be affected by the low Reynolds numbers present.

The profiles of the base geometry and new geometries are shown in Figure 2 and the governing model details are provided in Table 1. All four models had a nominal internal width of $500 \mathrm{~mm}$ and an orifice diameter of $50.8 \mathrm{~mm}$. A constant orifice diameter was chosen with the underlying assumption that total volumetric flux would be the same for each model meaning that the actual damping applied is also constant between the models. In hindsight the authors question the validity of this assumption, however are of the opinion that the data presented is still of value in its present form. 
Table 1: Model details $\left(\boldsymbol{A}_{\boldsymbol{w}}, \boldsymbol{A}_{\boldsymbol{o}}\right.$ is cross-sectional area at the static waterline and orifice area respectively)

\begin{tabular}{lcccc}
\hline \hline Model & $\begin{array}{c}\text { Chamber length } \\
\text { internal }(\mathbf{m m})\end{array}$ & $\begin{array}{c}\text { Damping } \\
\text { factor }\left(\boldsymbol{A}_{\boldsymbol{o}} / \boldsymbol{A}_{\boldsymbol{w l}}\right)\end{array}$ & $\begin{array}{c}\text { Chamber height } \\
\text { internal (mm) }\end{array}$ & $\begin{array}{c}\text { Chamber air } \\
\text { volume (litres) }\end{array}$ \\
\hline Base & 340 & 85 & 200 & 34 \\
10 degrees & 300 & 73 & 220 & 33 \\
20 degrees & 260 & 63 & 255 & 33 \\
30 degrees & 220 & 53 & 305 & 34 \\
\hline
\end{tabular}

115

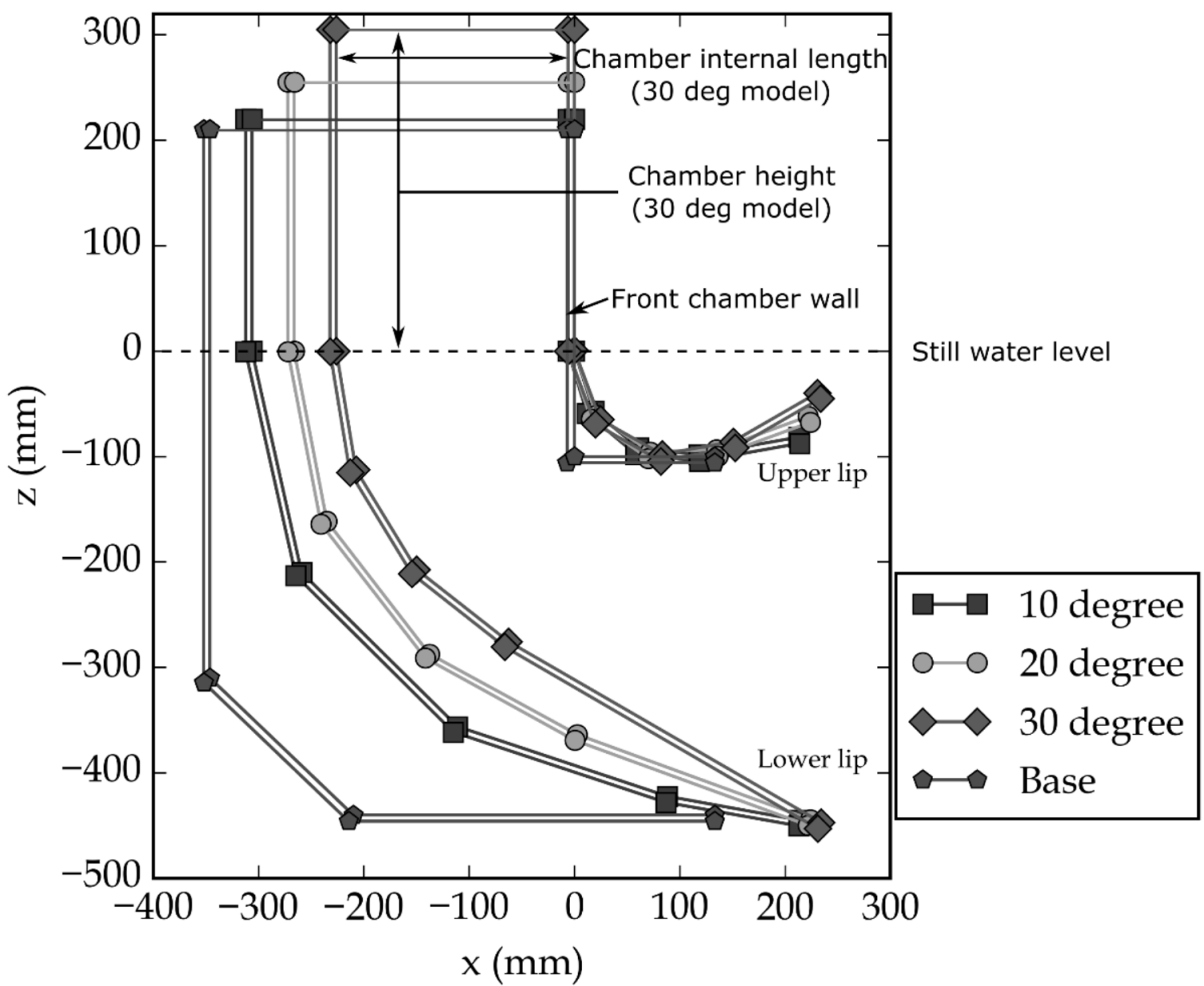




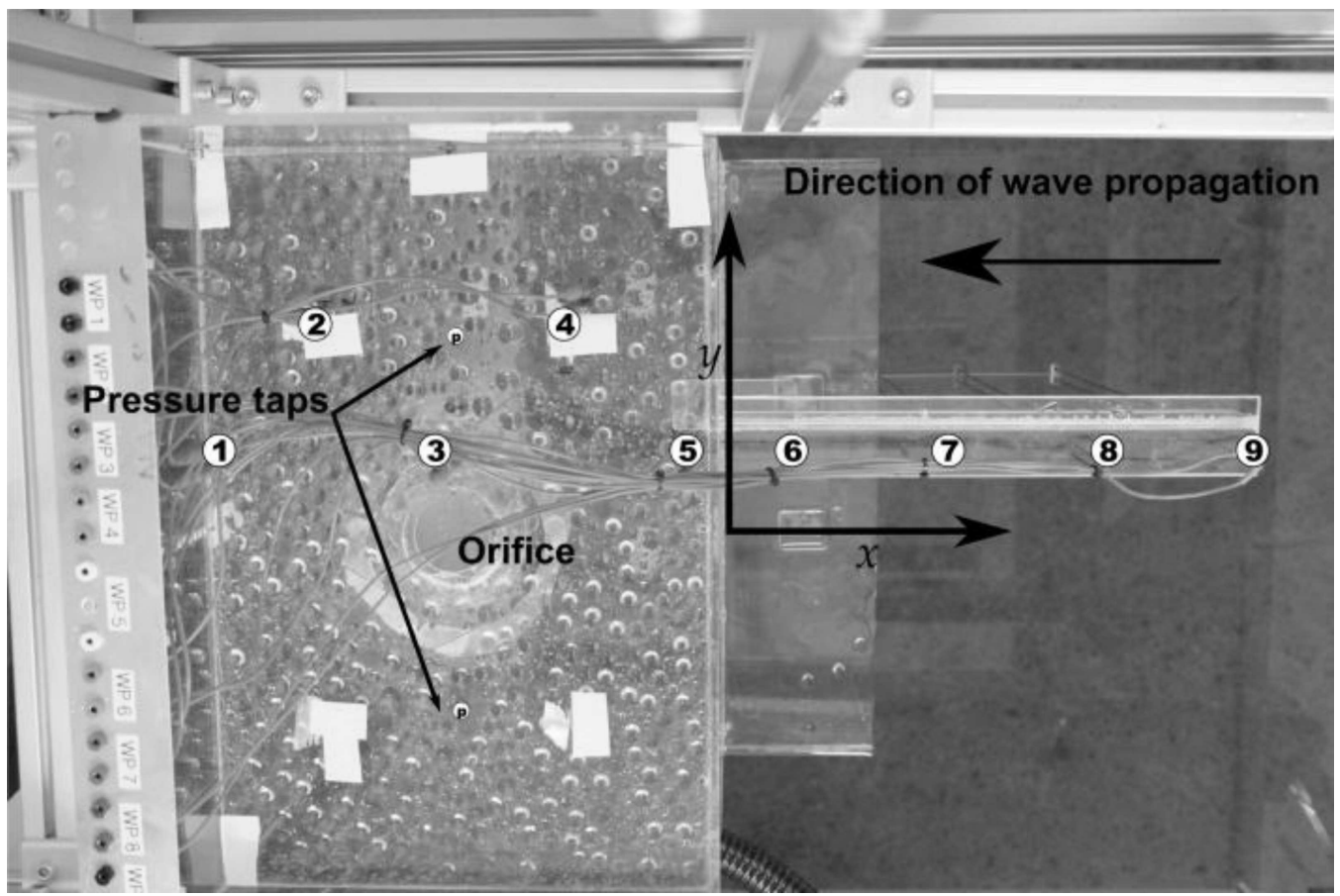

Figure 3: Plan view of the Base model showing the layout of the nine wave probes and position of the two pressure taps

\subsection{Apparatus}

Resistance type wave probes connected to Churchill wave probe monitors were used to obtain water elevation at multiple locations. Each model was fitted with five internal and four external wave probes as shown in Figure 3. A further two wave probes were deployed to capture the incident waves; one was positioned away from the model but adjacent to the front wall of the chamber and a second was located well up-wave of the model. The $x, y$ locations of all wave probes are detailed in Table 2 . The aft-most wave probe (\#1) intersected the aft chamber wall thus requiring the probe to be bent to create a non-vertical section below the intersection. This required a second calibration factor to be applied below the bend to correct for the change in slope.

Table 2: Wave probe $(\boldsymbol{x}, \boldsymbol{y})$ coordinates $(\mathrm{mm})$

\begin{tabular}{llllllllllllll}
\hline Model & $\begin{array}{l}\text { Adjacent } \\
\text { Probe }\end{array}$ & $\begin{array}{l}\text { Upstream } \\
\text { Probe }\end{array}$ & Probe 1 & Probe 2 & Probe 3 & Probe 4 & Probe 5 & Probe 6 & Probe 7 & Probe 8 & Probe 9 \\
\hline 10 degree & $(0,1313)$ & $(1008,-1472)$ & $(-296,50)$ & $(-231,150)$ & $(-156,50)$ & $(-81,150)$ & $(-16,50)$ & $(50,50)$ & $(150,50)$ & $(251,50)$ & $(350,50)$ \\
20 degree & $(0,1313)$ & $(1008,-1472)$ & $(-259,50)$ & $(-206,150)$ & $(-136,50)$ & $(-66,150)$ & $(-13,50)$ & $(50,50)$ & $(150,50)$ & $(250,50)$ & $(350,50)$ \\
30 degree & $(0,1313)$ & $(1008,-1472)$ & $(-214,50)$ & $(-176,150)$ & $(-115,50)$ & $(-60,150)$ & $(-16,50)$ & $(50,50)$ & $(150,50)$ & $(251,50)$ & $(350,50)$ \\
Base & $(0,1310)$ & $(1008,-1472)$ & $(-335,50)$ & $(-260,150)$ & $(-178,50)$ & $(-90,150)$ & $(-20,50)$ & $(50,50)$ & $(150,50)$ & $(250,50)$ & $(350,50)$
\end{tabular}

Two pressure transducers monitored chamber pressure (2 psig Endevco Model 8510B-2 powered and conditioned by an Endevco 136 Voltage Amplifier) and were positioned as shown in Figure 3.

Pressure transducer, wave probe and PIV trigger data was sampled by a 16 bit National Instruments PCI-6254-M ADC card at a rate of $1000 \mathrm{~Hz}$ with physical connections through a rack mounted BNC terminal block (NI BNC-2090).

2D PIV was performed during experimentation using LaVision GMBH hardware and software. The light sheet was generated by underwater light sheet optics and a dual cavity $120 \mathrm{~mJ} \mathrm{Nd}-\mathrm{Yag}$ laser (Newave Solo). Focussed light sheet thickness was approximately $4 \mathrm{~mm}$. Image pairs were acquired using a LaVision sCMOS camera (16 bit, $2560 \times 2160$ pixels) with an interframe time of $10 \mathrm{~ms}$ and acquired at a double-frame rate of $15 \mathrm{~Hz}$. PIV timing was controlled using a LaVision programmable 
timing unit PTU-9. A trigger pulse was generated at the time of each image pair by the PTU and recorded as an analog channel adjacent to the wave probe and pressure transducer data.

Self-manufactured neutrally buoyant fluorescing particles in a size range of 35-75 micron were used as seeding particles, manufacture was by the process as described by [18] using a modified method of that first described by Turney et al.[19].

\subsection{Phase-averaging}

Phase-averaging was applied to PIV, wave probe and pressure transducer data. Unless otherwise stated the wave probe adjacent to the OWC model was used as the signal for phase-averaging. A wave cycle is equivalent to a standard zero-up-crossing wave. Wave period and phase-shift were identified by using optimization algorithms to minimize the difference between the wave probe signal and a linear wave approximation of the expected wave by modifying the approximated wave height, period and phase-shift. The phase of data then corresponds to:

$$
\left(\frac{t}{T}\right)_{i}=\left(\phi+\frac{t_{i}}{T}\right) \bmod 1
$$

where $\phi$ is phase shift, $T$ is wave period and $t_{i}$ is the time corresponding to the data and mod is the modulo operator (in this case the remainder after division by 1 ).

Wave probe and pressure transducer data were ensemble averaged using 100 bins across a wave cycle. Due to the complexity introduced by the presence of a free-surface in image, and limited number of images; a hybrid phase-averaging algorithm was used to phase-average PIV data. The method consists of fitting cubic B-splines to ensemble-averaged data (in amplitude and phase) which is described in detail in Fleming [18]. The parameters used to phase-average PIV data are listed in Table 3.

Table 3: Parameters for phase-averaging PIV vector data. See [20].

\begin{tabular}{|c|c|c|}
\hline Parameter & Value & Description \\
\hline nmin & 22 & Minimum number of vectors per phase \\
\hline $\mathrm{mr}$ & 0.5 & Ratio of masked to total vectors as a limit for masking \\
\hline pmod & 'average' & Indicates to average the phase rather than using the 'bin' value \\
\hline uncPow & 0.5 & $\begin{array}{l}\text { The power to which the number of samples is raised for } \\
\text { calculating uncertainty using the standard deviation of samples. } \\
\text { (Typical value is } 0.5 \text { for one dimensional data) }\end{array}$ \\
\hline
\end{tabular}

\subsection{Orifice flow}

Separate inflow $\left(C_{i n}\right)$ and outflow $\left(C_{\text {out }}\right)$ coefficients were determined according to the 'in-situ' calibration method described by Fleming and Macfarlane [21] utilising water chamber wave probes and pressure transducer data:

$$
\begin{aligned}
& C_{\text {in }}=0.567 \\
& C_{\text {out }}=0.630
\end{aligned}
$$

Using these coefficients volumetric flow was calculated from pressure transducer information using an orifice flow equation modified to permit negative values of pressure differential. Separate flow coefficients were applied based on flow direction, data corresponding to absolute pressures less than $1 / 3$ of RMS were replaced with spline interpolated values as in [21]: 


$$
Q={ }_{\operatorname{sign}}(\Delta p) C_{0} A_{o} \sqrt{2|\Delta p| / \rho}
$$

171 where $Q$ is volumetric flow rate, $\rho$ is density, $\Delta p$ is chamber differential pressure and $A_{o}$ is the orifice 172 cross-sectional area. 'sign' is used to indicate reversed flow: inhalation has negative pressure

173 differential and corresponding 'negative' flow. Plots of phase-averaged pressure and flow for each

174 model and wave frequency tested are included in Appendix B.

\section{$175 \quad 2.5$ OWC performance}

176 Power (energy flux) per unit length for monochromatic waves is

$$
P=\frac{\rho g^{2} H^{2} T}{32 \pi}
$$

178 where $g$ is gravitational acceleration, $H$ is wave height and $T$ is wave period.

179 Power dissipated at the orifice (simulated power take-off) is

$$
P_{\text {рто }}=\Delta p Q
$$

181 Capture width is defined as the ratio of power dissipated to the power of the incoming wave is

$$
C W=\frac{P_{\text {Рто }}}{P L}
$$

Where $L$ is the chamber width

Two-dimensional total kinetic energy of the velocity field per unit width [7] is

$$
E_{k}=\frac{1}{2} \rho_{w} \mathrm{dxdz} \sum_{x, z} V_{(x, z)}^{2}
$$

where $\rho_{w}$ is water density, $\mathrm{dx}$ is pixel width, $\mathrm{dz}$ is pixel height and $V_{(x, \mathrm{z})}$ is the velocity vector component and assumes the third velocity component is zero.

Average kinetic energy of $n$ independent velocity fields is

$$
\overline{\mathrm{E}}_{\mathrm{k}_{(\mathrm{i}, \mathrm{j})}}=\frac{1}{\mathrm{~N}} \sum_{\mathrm{n}=1}^{\mathrm{N}} \mathrm{E}_{\mathrm{k}_{\mathrm{n}(\mathrm{i}, \mathrm{j})}}
$$

where $i, j$ is the column and row respectively.

Two-dimensional vorticity [7] is

$$
\text { vor }=\frac{1}{2}\left(\frac{\partial \mathrm{v}}{\partial \mathrm{x}}-\frac{\partial \mathrm{u}}{\partial \mathrm{z}}\right)
$$




\section{Results and discussion}

193 Results presented here are of two types: the first compares the power output performance of the OWC 194 geometries, while the second examines how the change in geometry impacts the flow fields inside the 195 device with implications for future geometry design.

\subsection{Overall performance}

The comparison of overall performance was achieved using two methods; capture width (Figure 4 a) and average power extracted (Figure $4 \mathrm{~b}$ ). By both metrics, on average the 10 degree model gave the best overall performance. The performance gains are modest and the usefulness is questionable since the power gains are mostly at the peak rather than an overall performance gain, hence depending on the full-scale arrangement it may not be feasible to extract the additional energy (depends on power take-off equipment). Using this information alone, one might conclude that there is no reason to adjust the geometry; however, analysis using the flow fields provide compelling arguments for modifications.

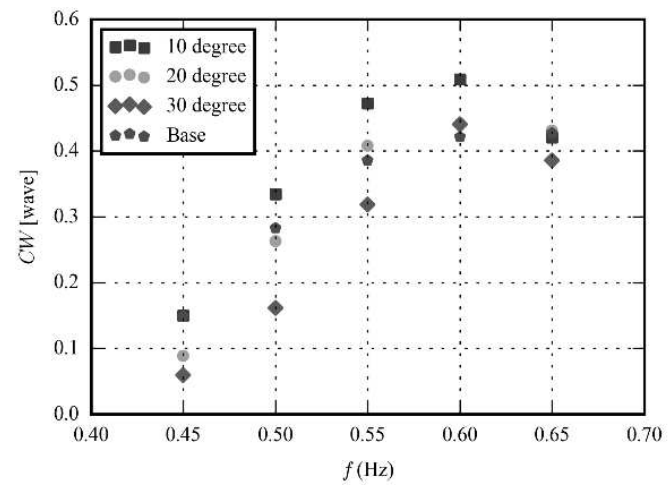

a)

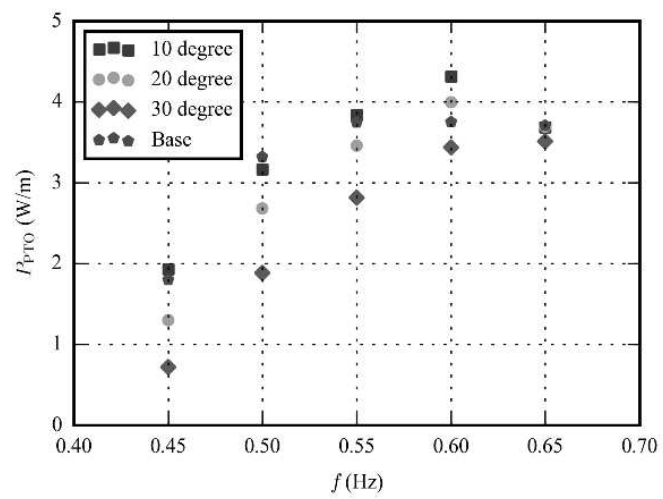

b)

Figure 4: Results for all four models at an incident wave height of $0.07 \mathrm{~m}$ at various monochromatic wave frequencies: a) capture width and b) power extracted (per model width)

Replotting power as a function of wave number multiplied by chamber length (Figure 5) rather than wave frequency is a means of comparing the effect of the different chamber lengths between the geometries. If we assume that it is desirable to maintain a consistent power output for the incoming wave climate (rather than maximise the peak) then it can be deduced that the ratio $k a$ should be greater than 0.32 , below which the power extracted rapidly drops off. Hence, a rational approach to selecting the chamber length for an OWC can be deduced by considering the lowest frequency 'design' wave. That corresponds approximately to a chamber length equal to 0.06 times the maximum expected wavelength. However this rule of thumb is only applicable to a deep water device and the level of damping should also be considered.

The relatively early drop off in power that occurs for all new geometries when compared to base geometry at the higher wave frequencies is due to the added void created behind the upper-lip, the implications of which are discussed further in the following section. 


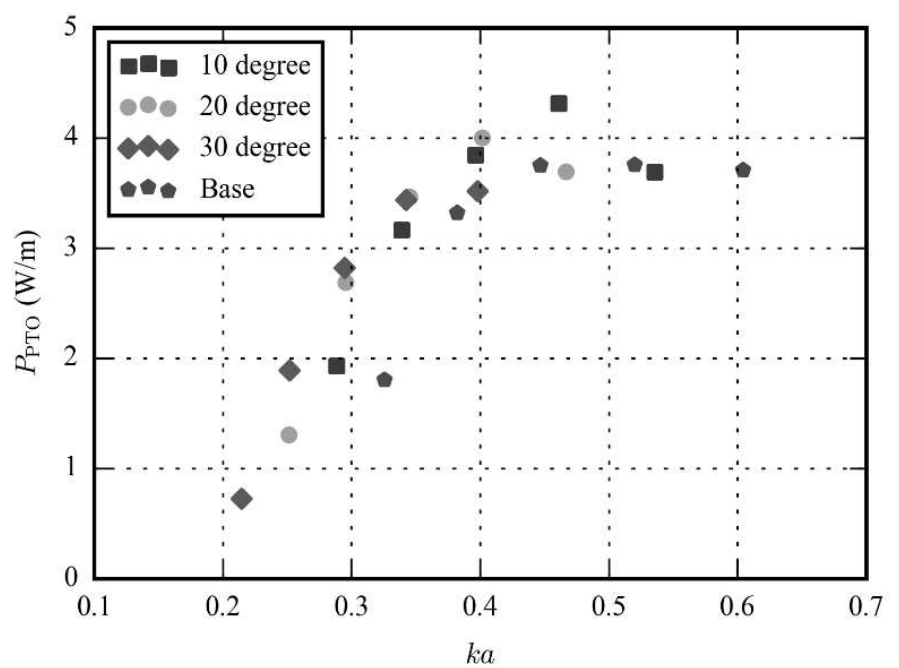

220 Figure 5: Results for all four models at an incident wave height of $0.07 \mathrm{~m}$ at various monochromatic wave frequencies: 221 power per model width as a function of $\boldsymbol{k} \boldsymbol{a}$, where $\boldsymbol{k}$ is wave number $\left(\frac{2 \pi}{\lambda}\right), \boldsymbol{a}$ is chamber length and $\boldsymbol{\lambda}$ is wavelength

222 Pumped volume is calculated from the integral of the absolute volumetric flow over a wave cycle (in time domain) which is approximately equal to twice the value of the product of the maximum water level excursion and the chamber cross-sectional area (ignoring water-column slosh it would be the same). In Figure 6 pumped volume appears to be loosely related to capture width, in that the rankings approximately correspond. Pumped volume is directly related to mass plus added mass, from which it may be possible to predict resonant frequency based on variables including: wave frequency, chamber length, lower lip submergence and orifice diameter.

Peak pumped volume is linked to resonance by maximum oscillation amplitude (ignoring water column slosh). Peak pumped volume occurs near $0.5 \mathrm{~Hz}$ for all models, with exception of the 30 degree model which occurs near $0.55 \mathrm{~Hz}$. Again, the 10 degree geometry has the best overall performance.

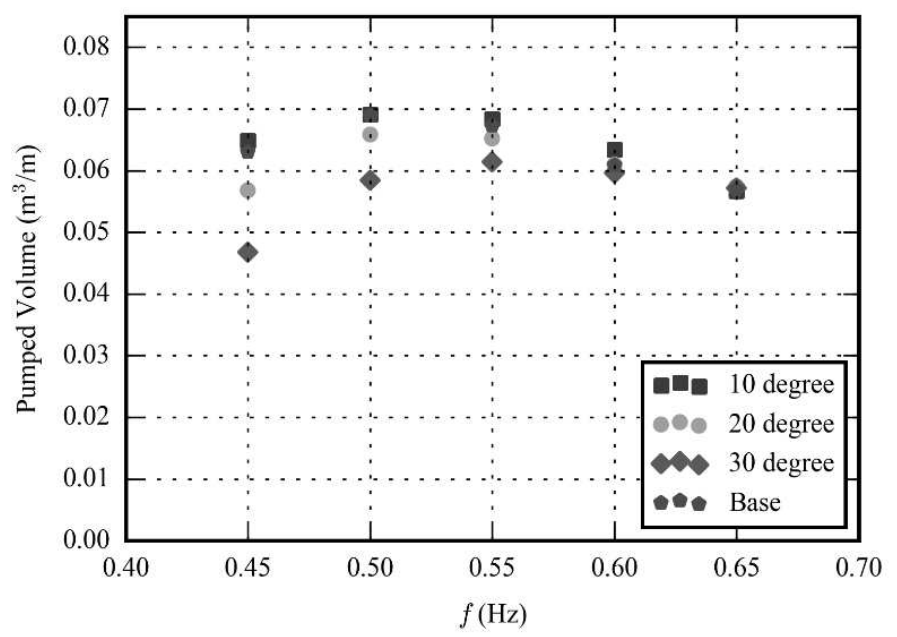




\subsection{Performance of Geometry}

237 To assess geometry performance it is necessary to isolate the geometry performance from other aspects of the performance of the OWC, namely interaction with the power-take-off. Three methods have been developed for this assessment utilising the PIV velocity field data:
1. Kinetic energy as a function of vorticity;
2. Average vorticity;
3. Average kinetic energy.

Figure 7 includes plots of kinetic energy as a function of vorticity for four different incident wave frequencies. These plots show the proportion of kinetic energy of the entire area of interest exceeding the vorticity value. The kinetic energy has been normalised enabling direct comparison of the proportion of kinetic energy with a vorticity exceeding that value. By example; a $100 \%$ efficient device (in terms of flow) would contain no voriticity component (irrotational flow), since from an energy balance consideration, irrotational flow is a loss only type of sink [7]. For all frequencies the new geometries have less energy associated with vorticity (losses) compared to the base geometry. This is mainly due to the additional segments in the upper-lip reducing the occurrence of rapid flow direction changes, but is not as pronounced as it could have been had cross-flow at the upper-lip been prevented (see Figure 8 for example).
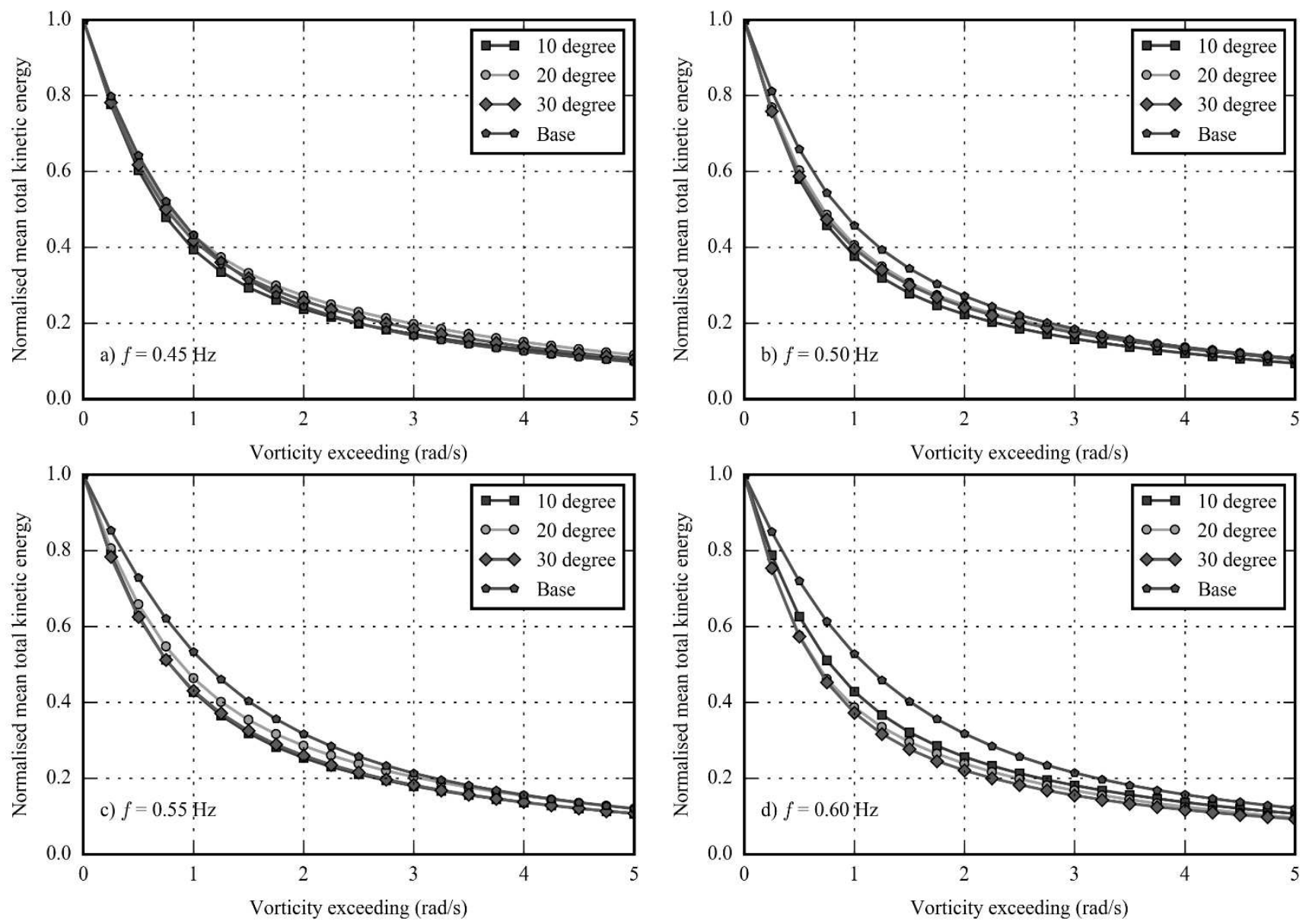

Figure 7: Normalised total kinetic energy as a function of vorticity at the centreline plane per model for $0.07 \mathrm{~m}$ high monochromatic waves at various wave frequencies as indicated

The second method uses visualisation of the temporally averaged two-dimensional vorticity of water 
$0.65 \mathrm{~Hz}$ ). The vortex at the lower-lip is due to separation of flow at the lower-lip, and in terms of energy balance is considered a loss. Visually, the magnitude of vorticity at the vertex of the upper-lip and chamber front wall is greater for the base geometry compared to the new geometries, and shows that the introduction of the segments was effective at reducing the vorticity at the upper-lip vertex.

There is a 'shadow' adjacent to the lower-lip which is due to the laser sheet being blocked by the lower-lip (an experimental artefact).

Experiments were also performed at two other nominal incident wave heights $(0.04$ and $0.05 \mathrm{~m})$ with similar trends to those found at $0.07 \mathrm{~m}$.
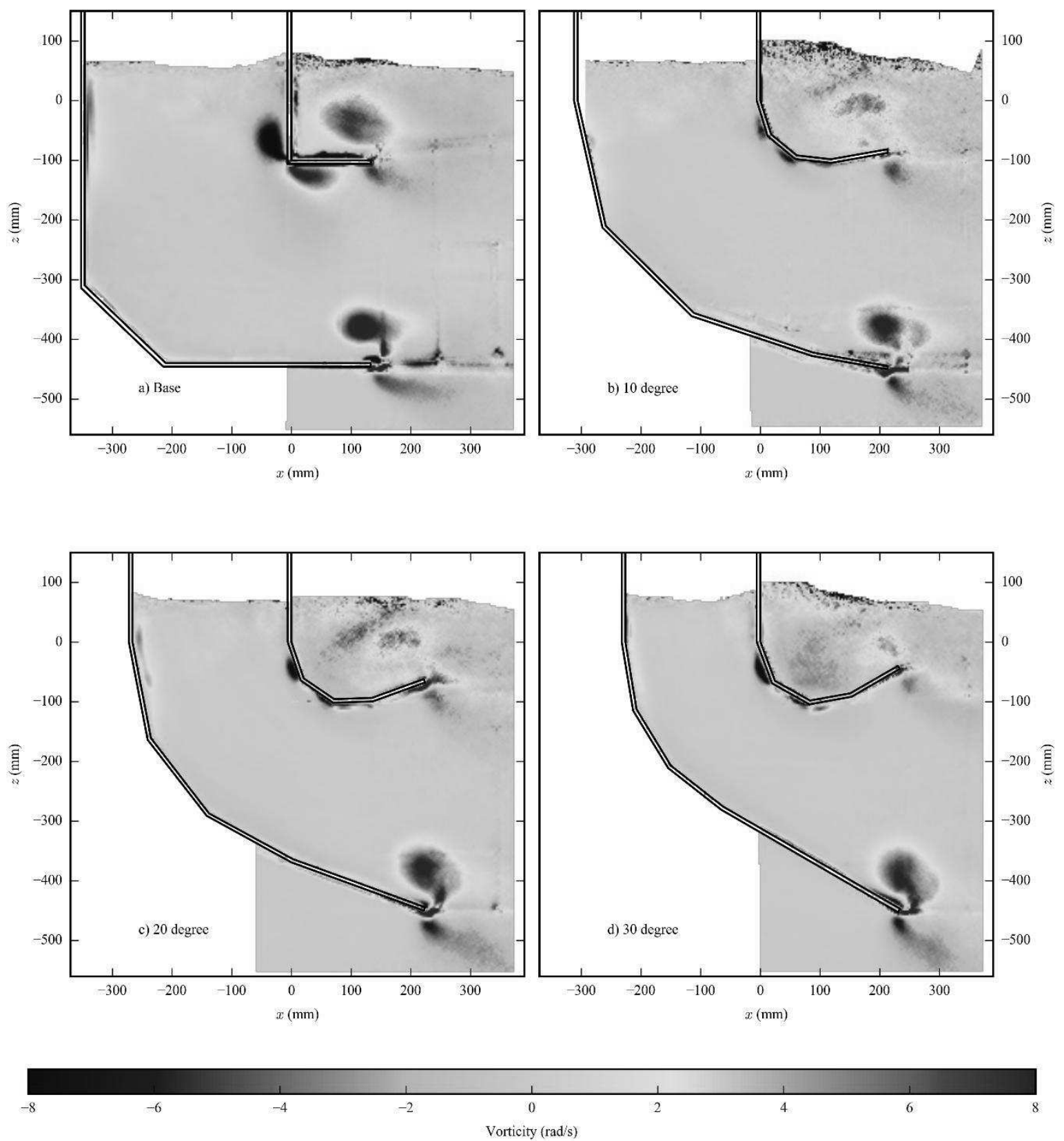

Figure 8: Average two-dimensional vorticity (1/s) over all wave frequencies tested for $0.07 \mathrm{~m}$ high monochromatic waves

The third method to assess geometry performance, shown in Figure 9, represents the normalised 
is concentrated at both the upper-lip and lower-lip and to a lesser extent at the vertex of the chamber front wall and the upper-lip, and at the mean water level inside the chamber.

273 For all models the proportion of energy concentration around the lower lip reduced as the wave 274 frequency increased (see Appendix A, where results for each of the five individual frequencies are 275 provided). This is likely due to change in wavelength and associated reduction in particle velocity at 276 the depth of the lower lip as wavelength reduces (wave frequency increases). Contrariwise for the 277 upper lip, as wave frequency increased; the proportion of energy concentrated around the upper lip 278 also increased.
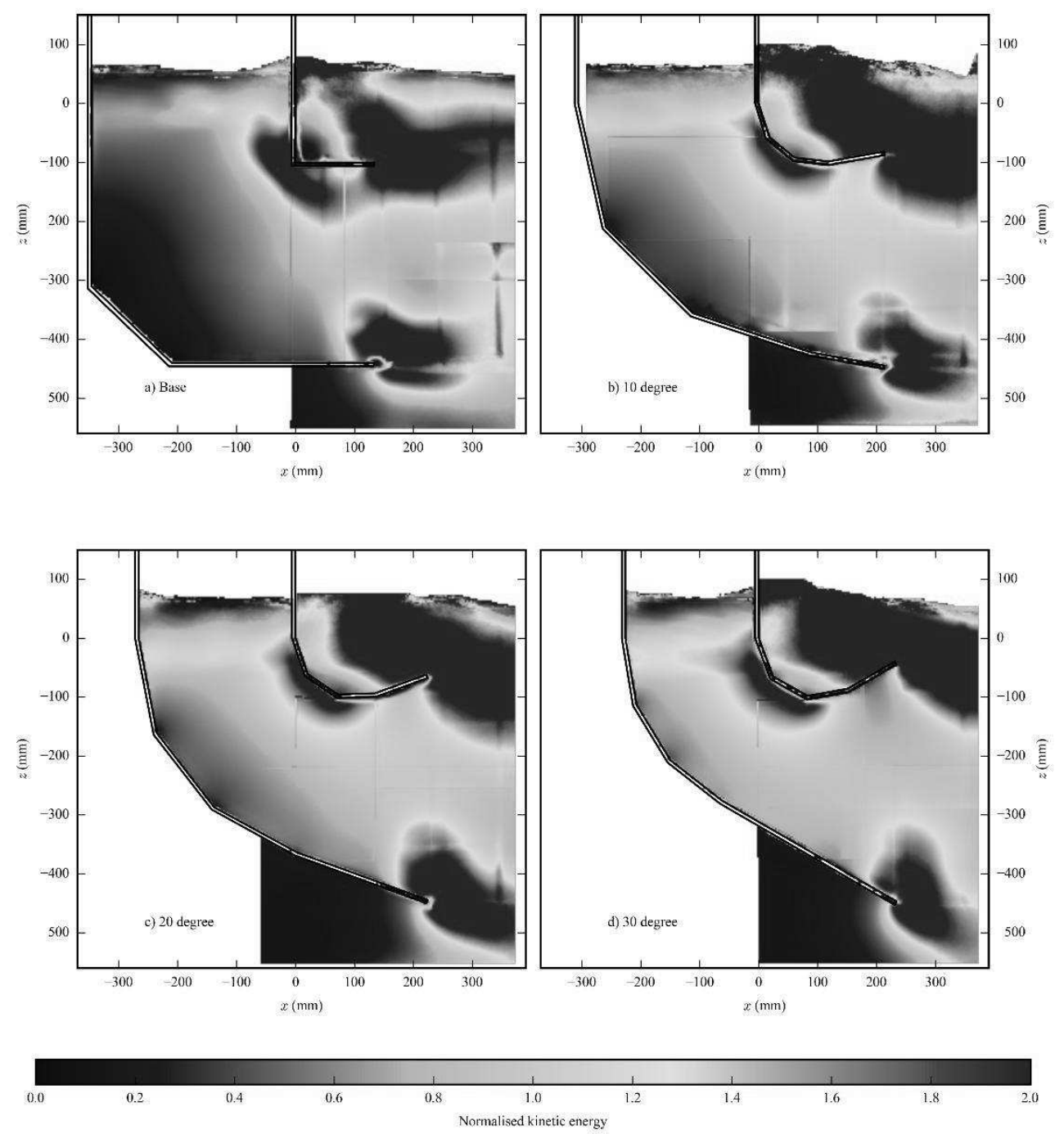

Figure 9: Normalised spatially averaged kinetic energy of all data available

Concentration of energy at the lower-lip corresponds with the previously mentioned vortex at the combination of the following:

- Lower-lip tip modified to a curve to limit separation of the oscillating flow;

- Lower-lip angled downwards;

- Lower-lip terminated earlier (to the left) and lower. 
Concentration of energy at the tip of the upper-lip varies depending on the geometry in question, but is due to separation of the oscillating flow at the sharp transition. This may be avoided by extending the upper-lip to above the maximum operation water level (still water level plus wave amplitude).

Concentration of energy behind the upper-lip is a new issue for the new geometry series which is caused by the void behind the angled upper-lip introducing a cross-flow (observed but not recorded). The cross-flow generated is erratic (turbulent) and should be prevented by filling the void behind the upper-lip.

\section{Conclusions}

An investigation into the effect of underwater geometry for forward-facing bent-duct OWC in deep water monochromatic waves has been undertaken. Using 'traditional' methods a direct comparison of the power outputs and capture width of the devices showed no significant difference in performance between geometries. However, a more detailed examination using PIV velocity fields reveals that:

1. Replacing sharp edges with a softer transition is effective at reducing energy loss via the production of vorticity;

2. Angling the upper-lip upwards improves energy capture, but the void created behind the upper-lip should be blocked to prevent cross flow;

Hence, the benefit of incorporating PIV velocity fields in parametric design of OWC underwater geometry has been demonstrated. Vorticity of the velocity fields represents energy which has been transformed into rotational vortices, from which it is not normally possible to extract energy. Kinetic energy of the velocity fields is another method for identifying inefficiencies, where uneven distribution of the kinetic energy will ultimately result in energy loss by shear between layers of uneven velocity.

Optimal geometry will remain a function of the wave climate and must be designed accordingly. Proportionally large geometry is unavoidable to extract adequate energy from low frequency waves. Conversely, if energy from higher frequency waves (wind seas) is dominant then it is possible to utilise a smaller device while maintaining relatively high efficiency. Softer transitions in underwater (and above water) geometry should be considered best practice.

\section{Acknowledgments}

This work was supported by the Australian Research Council [grant number LP110200129]. The authors acknowledge support from Thomas Mitchell Ferguson for assistance in performing the experiments and Liam Honeychurch for fabricating the models and infrastructure. The authors also thank Tom Denniss and Scott Hunter for technical input regarding geometry design.

\section{References}

[1] Sarmento A. Model-test optimization of an OWC wave power plant. International Journal of Offshore and Polar Engineering 1993;3:66-72.

[2] Falcão AFO, Henriques JCC. Oscillating-water-column wave energy converters and air turbines: A review. Renewable Energy 2016;85:1391-424. doi:10.1016/j.renene.2015.07.086.

[3] Falcão AFO, Henriques JCC. Model-prototype similarity of oscillating-water-column wave energy converters. International Journal of Marine Energy n.d. doi:10.1016/j.ijome.2014.05.002.

[4] Keulegan GH, Carpenter LH. Forces on cylinders and plates in an oscillating fluid. Journal of Research of the National Bureau of Standards 1958;60:423-40. doi:10.6028/jres.060.043. 
[5] Knott GF, Flower JO. Measurement of energy losses in oscillatory flow through a pipe exit. Applied Ocean Research 1980;2:155-64. doi:10.1016/0141-1187(80)90013-9.

[6] Brunold CR, Hunns JCB, Mackley MR, Thompson JW. Experimental observations on flow patterns and energy losses for oscillatory flow in ducts containing sharp edges. Chemical Engineering Science 1989;44:1227-44. doi:10.1016/0009-2509(89)87022-8.

[7] Fleming A, Penesis I, Macfarlane G, Bose N, Denniss T. Energy Balance Analysis for an Oscillating Water Column Wave Energy Converter. Ocean Engineering 2012;54:26-33. doi:10.1016/j.oceaneng.2012.07.002.

[8] Knott GF, Mackley MR. On Eddy Motions near Plates and Ducts, Induced by Water Waves and Periodic Flows. Philosophical Transactions of the Royal Society of London Series A, Mathematical and Physical Sciences 1980;294:599-623. doi:10.1098/rsta.1980.0070.

[9] Folley M, Whittaker T. Identification of Non-Linear Flow Characteristics of the Limpet Shoreline OWC. vol. 12, International Society of Offshore and Polar Engineers; 2002, p. 541-6.

[10] Tseng R-S, Wu R-H, Huang C-C. Model study of a shoreline wave-power system. Ocean Engineering 2000;27:801-21.

[11] McCormick ME, Altera AG. A Comparative Study of Two Capture Chamber Geometries. Utilization of Ocean Waves--wave to Energy Conversion, Amer Society of Civil Engineers; 1986.

[12] Koola PM, Ravindran M, Aswathanarayana PA. Studies on the Relative Performance of Three Oscillating Water Column Wave Energy Devices. Journal of Energy Resources Technology 1994;116. doi:10.1115/1.2906455.

[13] Hong K, Shin S-H, Hong D-C, Choi H-S, Hong S-W. Effects of Shape Parameters of OWC Chamber in Wave Energy Absorption, International Society of Offshore and Polar Engineers; 2007, p. 428-33.

[14] Dizadji N, Sajadian SE. Modeling and optimization of the chamber of OWC system. Energy 2011;36:2360-6. doi:10.1016/j.energy.2011.01.010.

[15] Rezanejad K, Bhattacharjee J, Guedes Soares C. Stepped sea bottom effects on the efficiency of nearshore oscillating water column device. Ocean Engineering 2013;70:25-38. doi:10.1016/j.oceaneng.2013.05.029.

[16] Mitchell Ferguson T, MacFarlane G, Fleming A, Penesis I. PIV investigation of 3-dimensional flow within an oscillating water column. International Journal of Marine Energy 2015;11:120 31. doi:10.1016/j.ijome.2015.06.004.

[17] Fleming A, Penesis I, Goldsworthy L, Macfarlane G, Bose N, Denniss T. Phase Averaged Flow Analysis in an Oscillating Water Column Wave Energy Converter. Journal of Offshore Mechanics and Arctic Engineering, ASME; 2011, p. 475-84. doi:10.1115/OMAE2011-49426.

[18] Fleming A, Penesis I, Macfarlane G, Bose N, Hunter S. Phase averaging of the velocity fields in an oscillating water column using splines. Proceedings of the Institution of Mechanical Engineers, Part M: Journal of Engineering for the Maritime Environment 2012;226:335-45. doi:10.1177/1475090212439826.

[19] Turney DE, Anderer A, Banerjee S. A Method for Three-Dimensional Interfacial Particle Image Velocimetry (3D-IPIV) of an Air-Water Interface. Measurement Science and Technology 2009;20.

[20] Fleming A. Phase-averaged analysis of an oscillating water column wave energy converter. University of Tasmania, Available at: http://eprints.utas.edu.au/15913/, 2012.

[21] Fleming A, Macfarlane G. In-situ orifice calibration for oscillating flow and improved performance prediction in oscillating water column model test experiments. 2nd Asian Wave and Tidal Energy Conference, Tokyo: 2014.

[22] Oliphant T, Ascher D. NumPy: Numerical Python. Livermore, California, USA. Available at: Http://numpy.scipy.org/: Lawrence Livermore National Laboratory; 2001. 


\section{Appendix A}

Average kinetic energy for $H=0.07 \mathrm{~m}$ and $f=0.45 \mathrm{~Hz}$
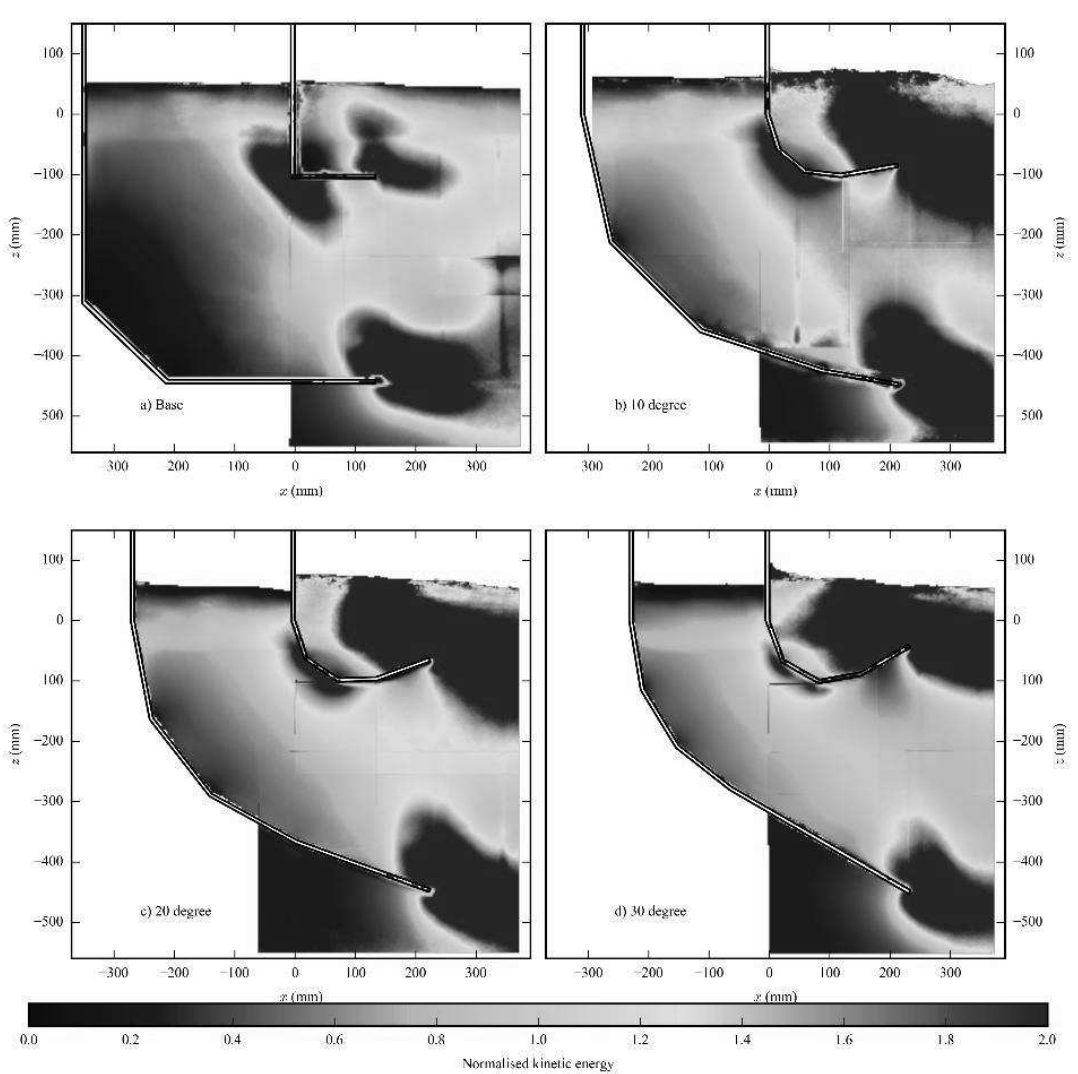

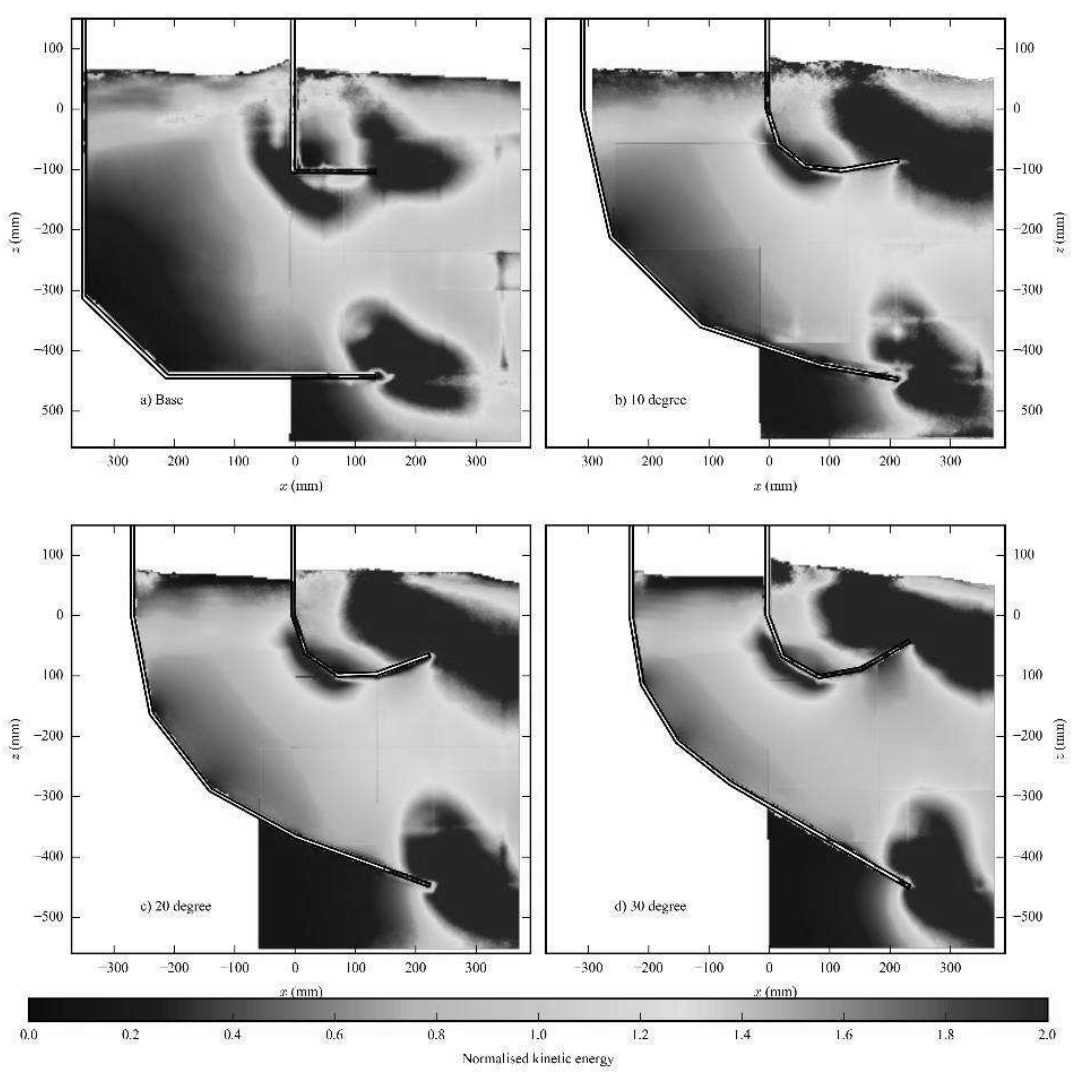

Average kinetic energy for $H=0.07 \mathrm{~m}$ and $f=0.55 \mathrm{~Hz}$
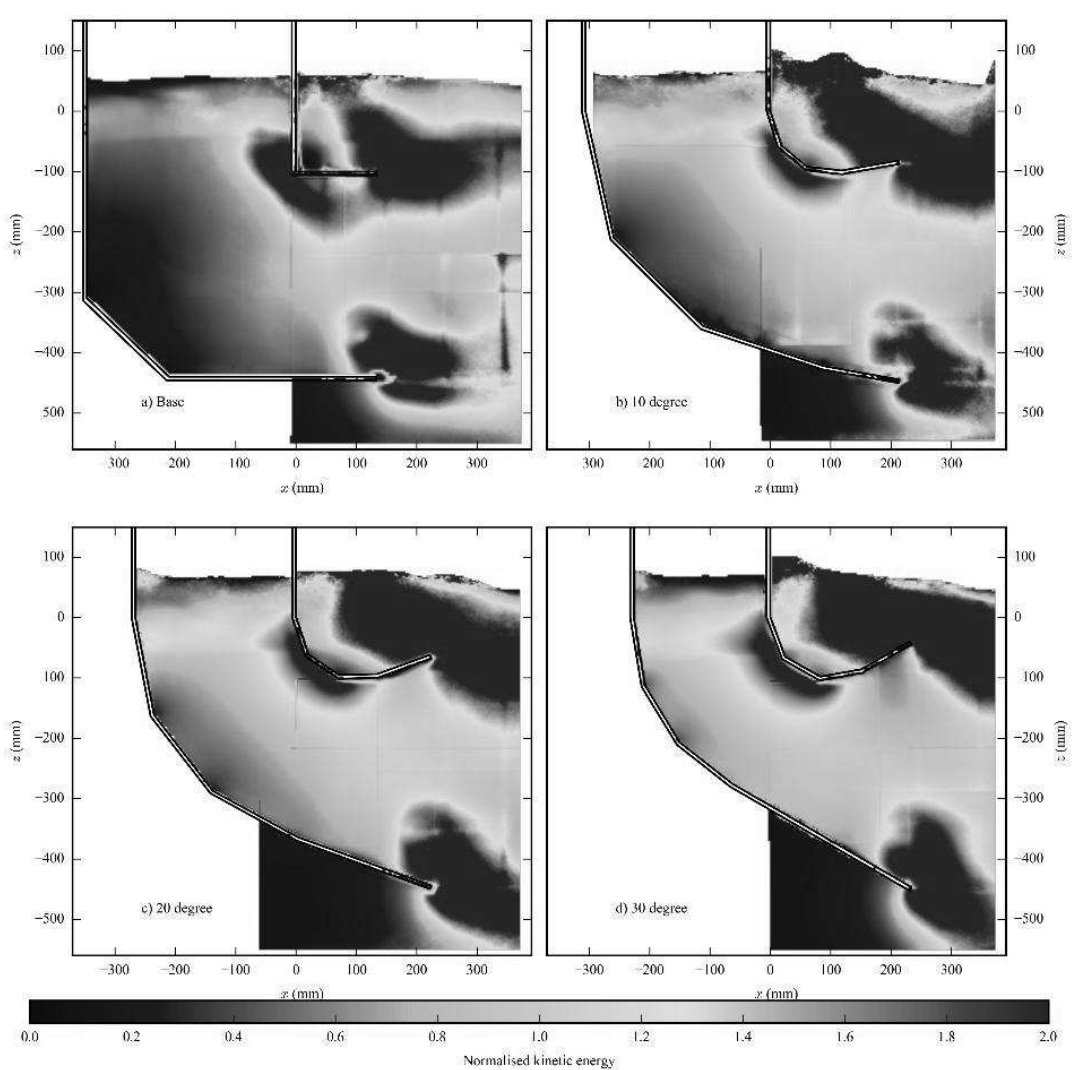

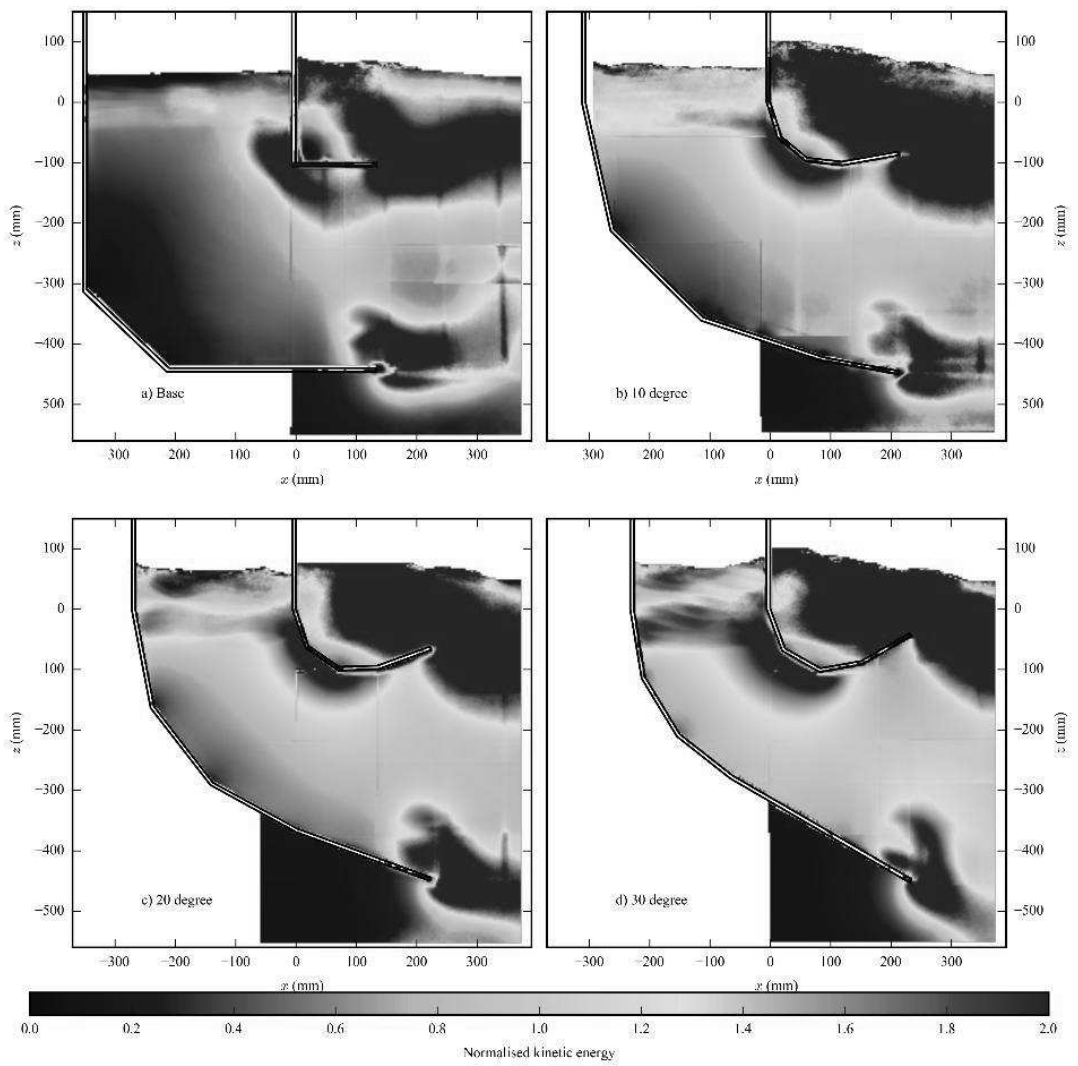

Average kinetic energy for $H=0.07 \mathrm{~m}$ and $f=0.65 \mathrm{~Hz}$
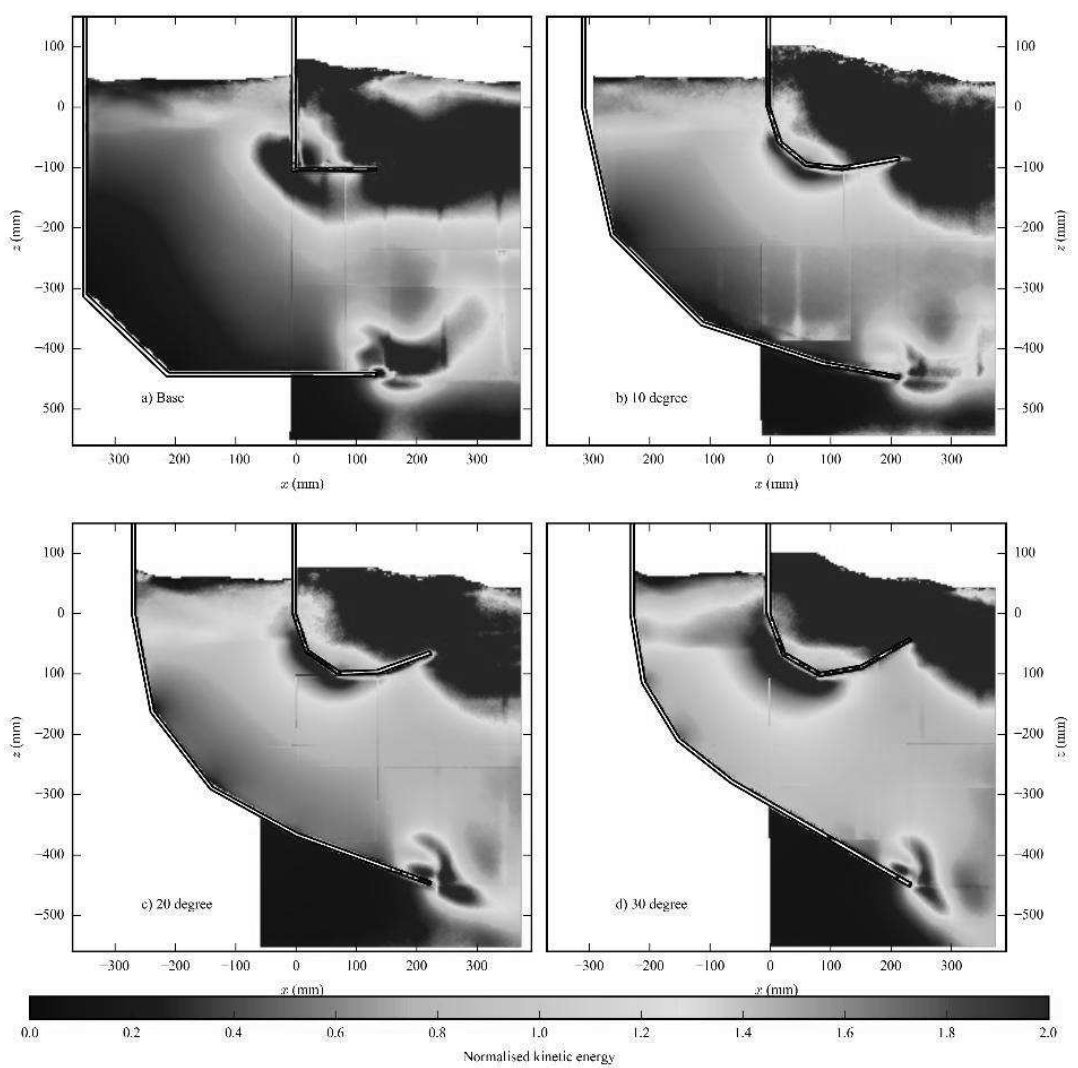
Appendix B: Phase averaged air flow and pressure

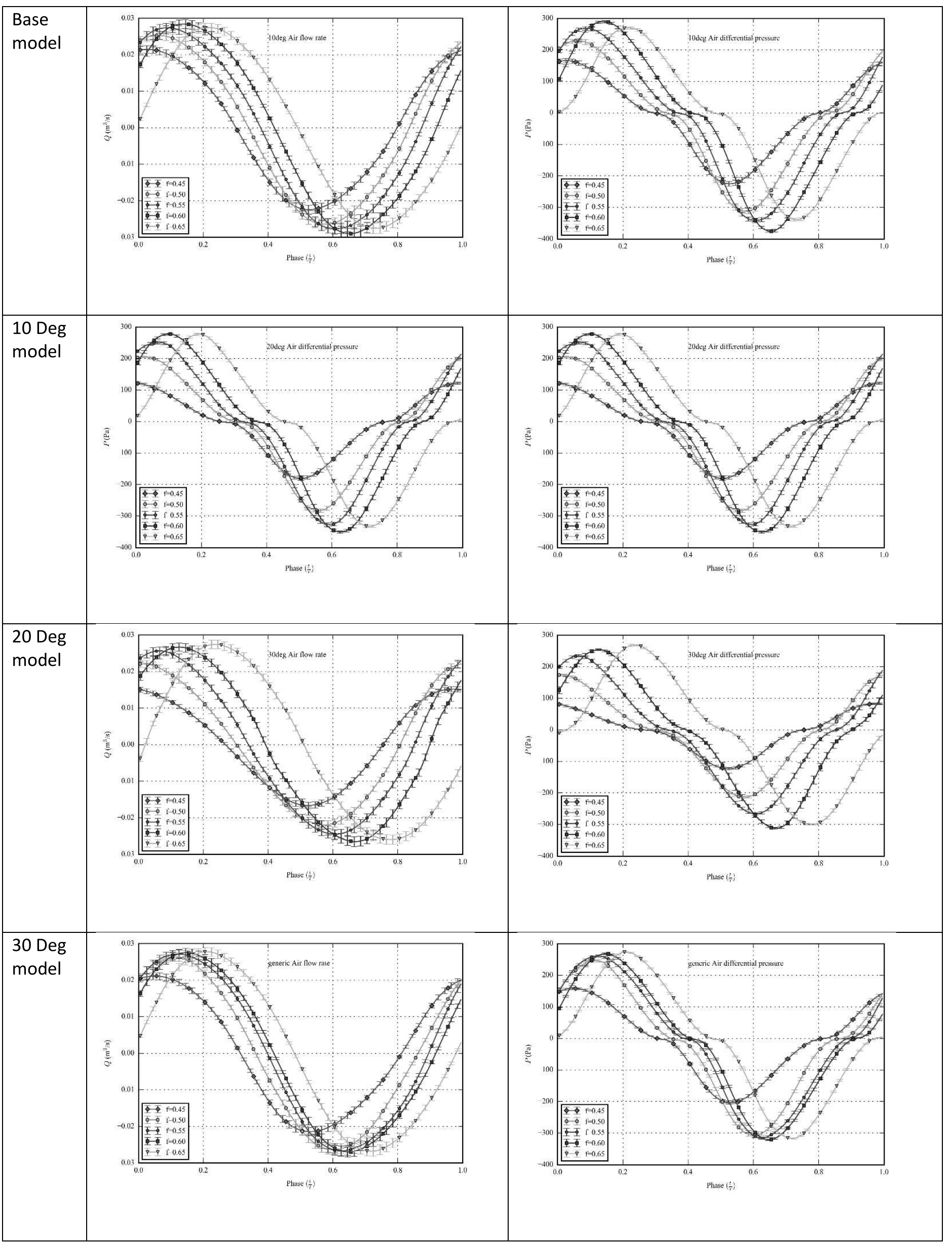


Figure 3: Experimental setup shown in cut-out of AMC towing tank, pulsed laser light sheet is shown extending from the laser arm (laser not shown)

Figure 4: Profiles of each of the four OWC model geometries tested

Figure 3: Plan view of the Base model showing the layout of the nine wave probes and position of the two pressure taps

Figure 4: Results for all four models at an incident wave height of $0.07 \mathrm{~m}$ at various monochromatic wave frequencies: a) capture width and b) power extracted (per model width)

Figure 5: Results for all four models at an incident wave height of $0.07 \mathrm{~m}$ at various monochromatic wave frequencies: power per model width as a function of $\boldsymbol{k a}$, where $\boldsymbol{k}$ is wave number $\left(\frac{2 \pi}{\lambda}\right), \boldsymbol{a}$ is chamber length and $\boldsymbol{\lambda}$ is wavelength

Figure 6: Total volumetric flow per model width through orifice over one wave cycle for $0.07 \mathrm{~m}$ monochromatic wave height.

Figure 7: Normalised total kinetic energy as a function of vorticity at the centreline plane per model for $0.07 \mathrm{~m}$ high monochromatic waves at various wave frequencies as indicated

Figure 8: Average two-dimensional vorticity $(1 / \mathrm{s})$ over all wave frequencies tested for $0.07 \mathrm{~m}$ high monochromatic waves

Figure 9: Normalised spatially averaged kinetic energy of all data available

\section{Table Captions}

Table 4: Model details ( $\boldsymbol{A}_{\boldsymbol{w}}, \boldsymbol{A}_{\boldsymbol{o}}$ is cross-sectional area at the static waterline and orifice area respectively)

Table 5: Wave probe $(\boldsymbol{x}, \boldsymbol{y})$ coordinates $(\mathrm{mm})$

Table 6: Parameters for phase-averaging PIV vector data. See [20]. 
Model

Laser Arm

Camera 1

$$
\begin{aligned}
& \text { Field of } \\
& \text { view }
\end{aligned}
$$

Direction of

Wave propagation 
Figure

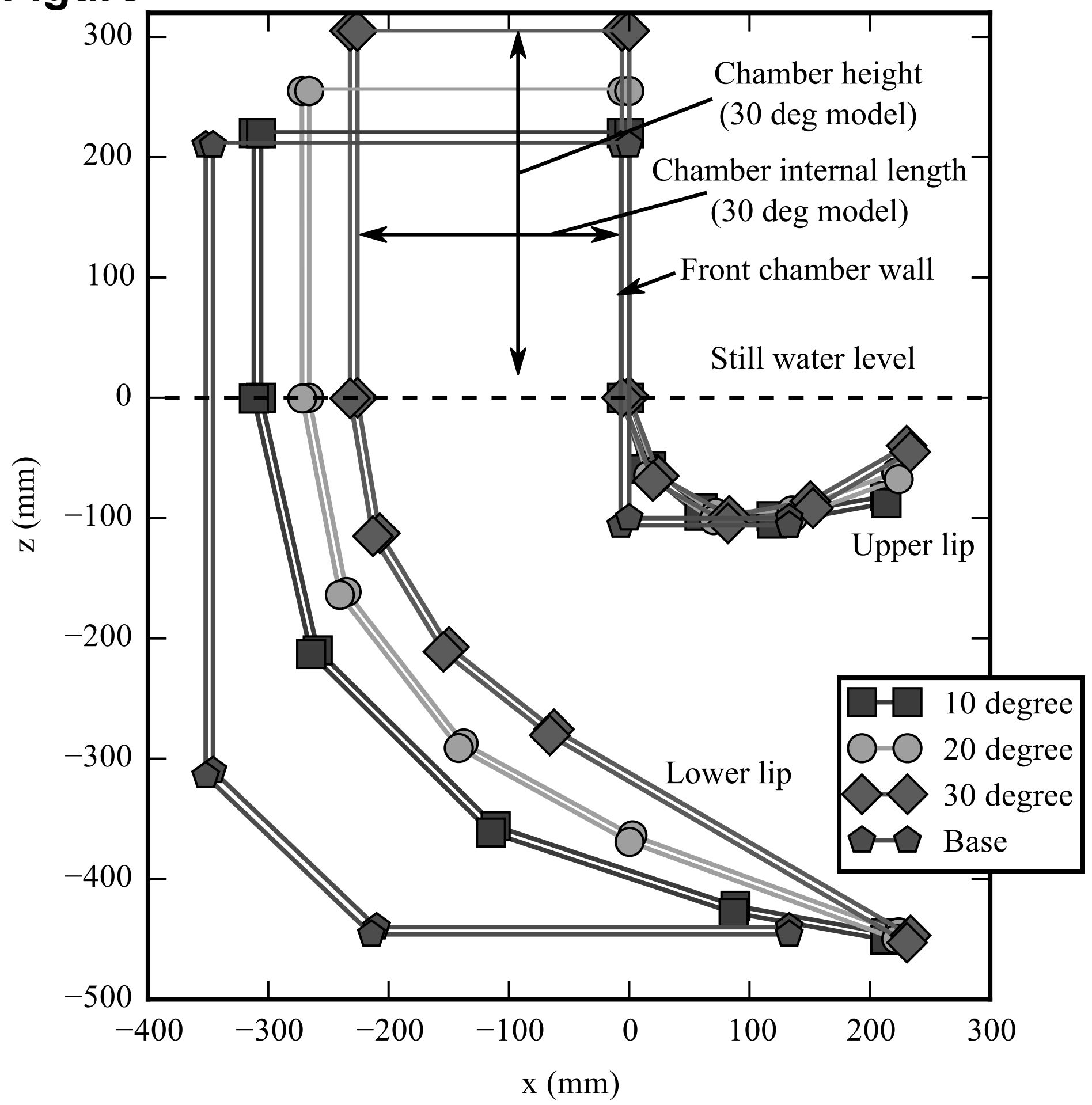




\section{Figure}

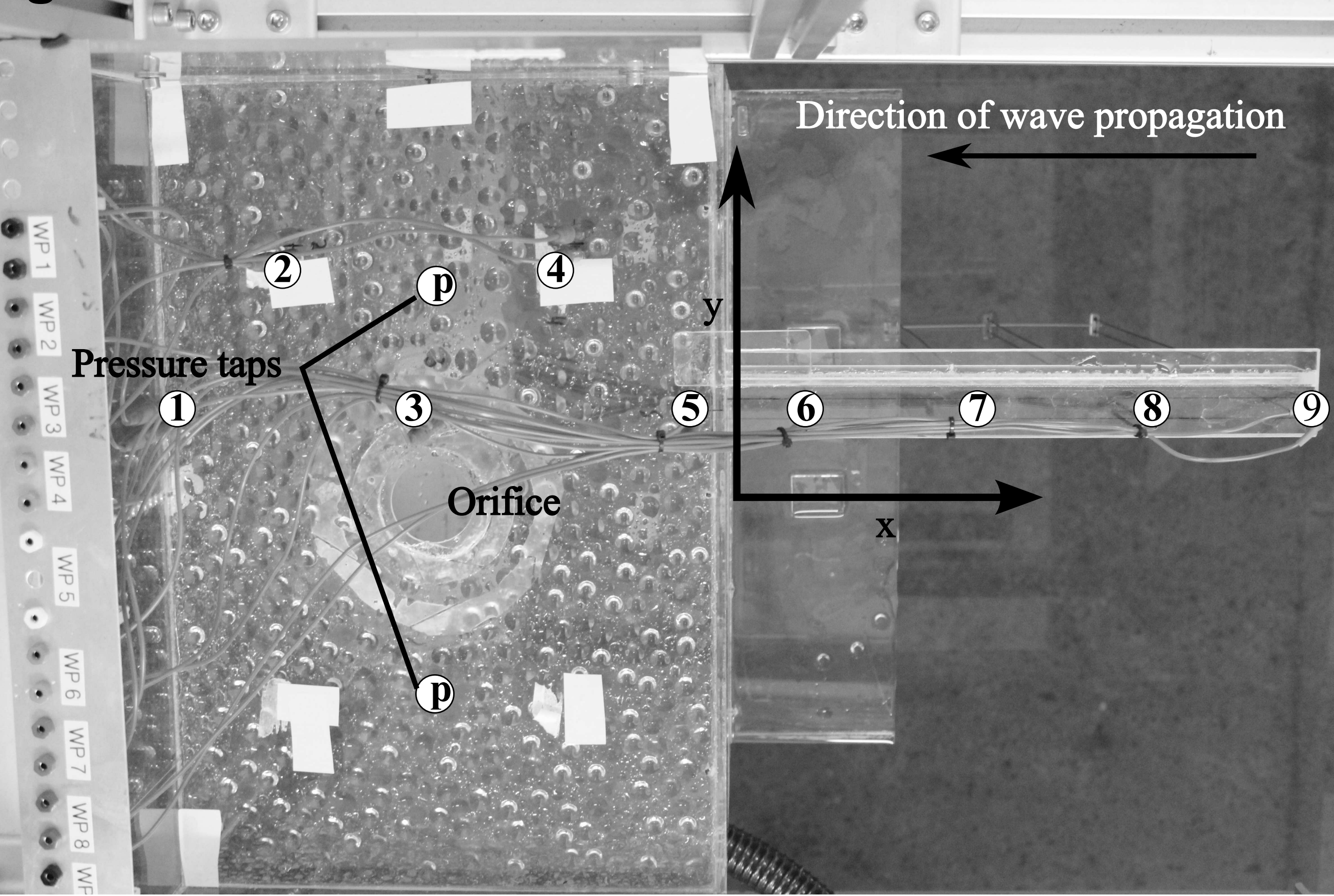


Figure

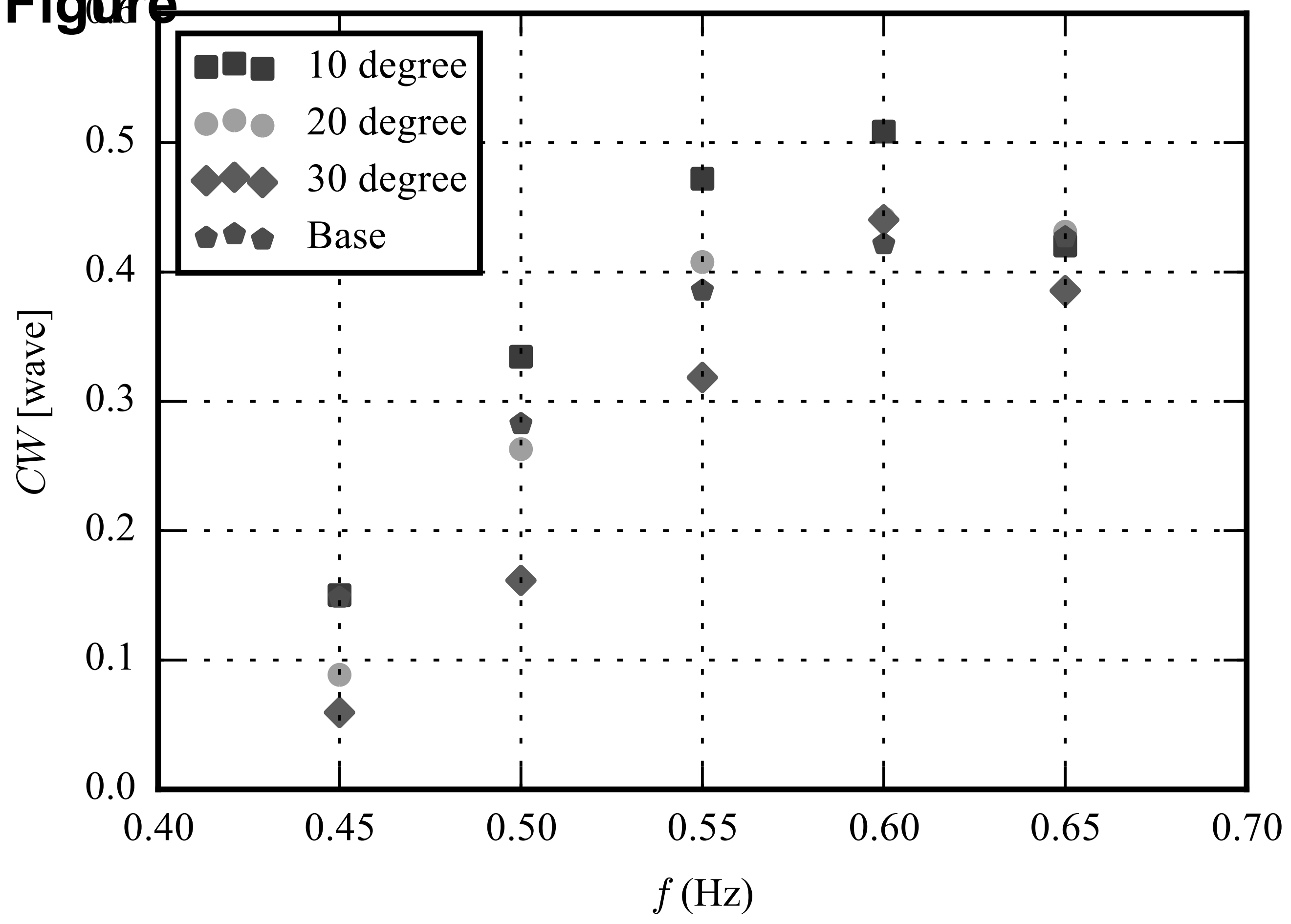


Figure

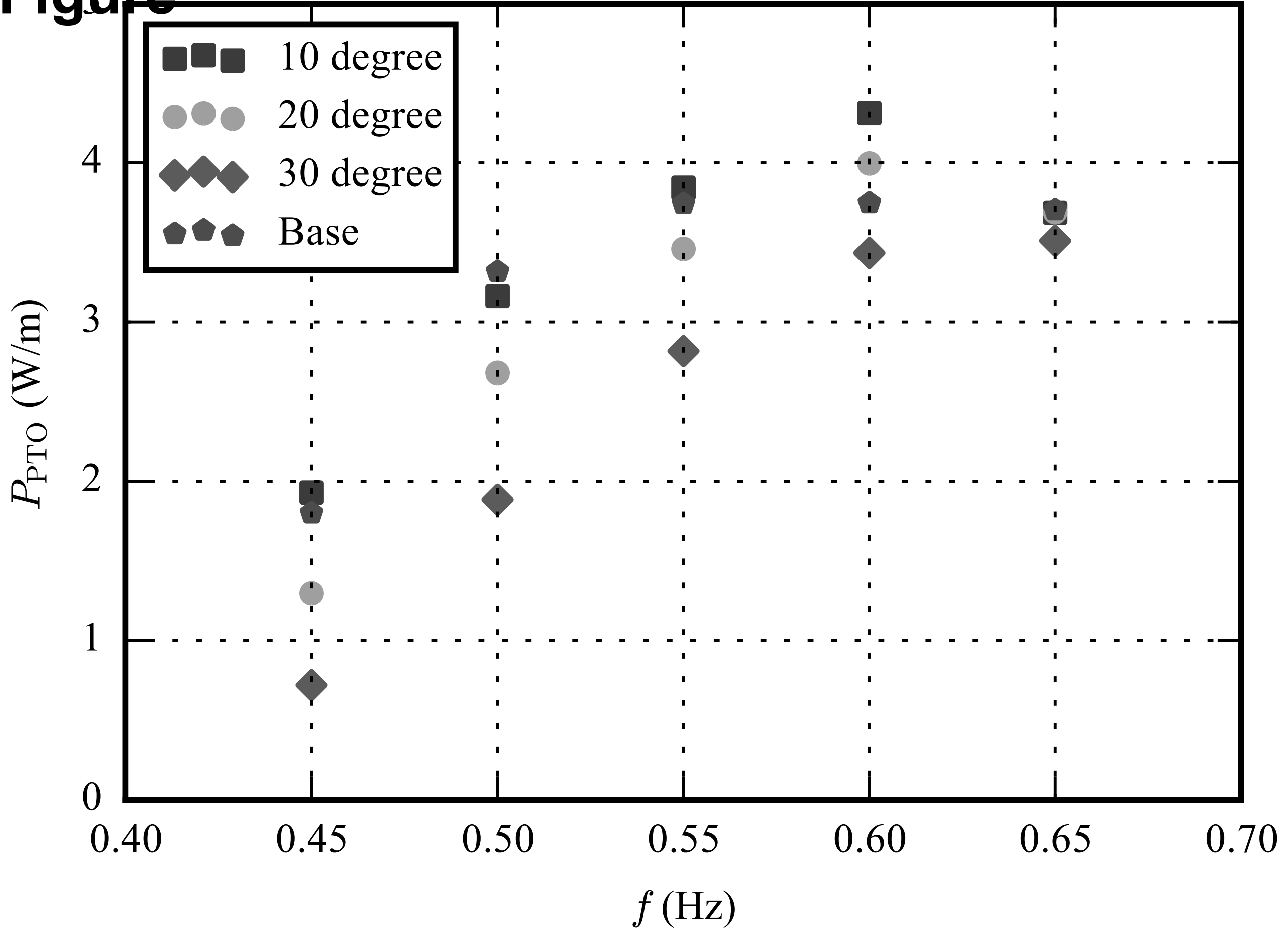




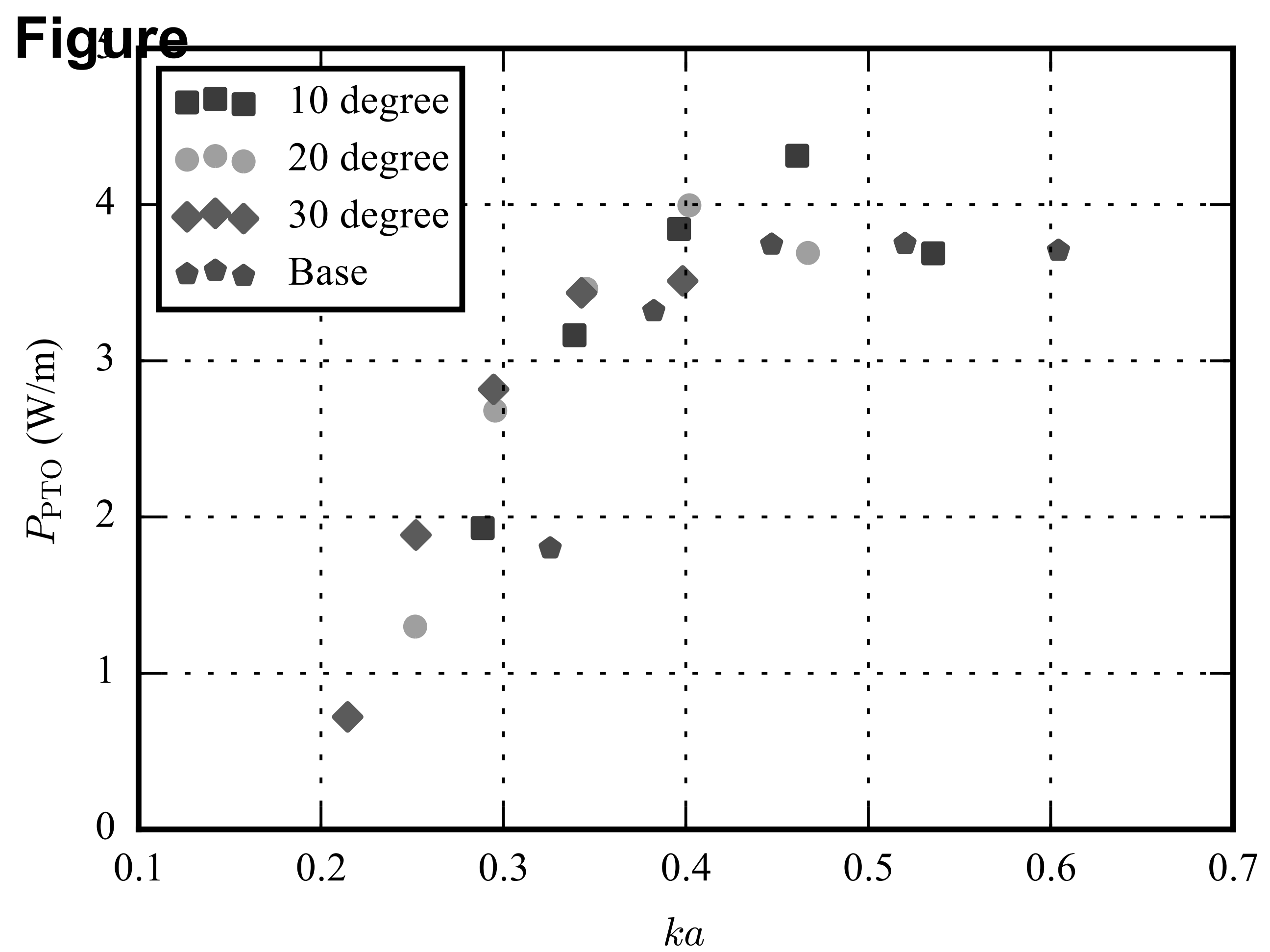




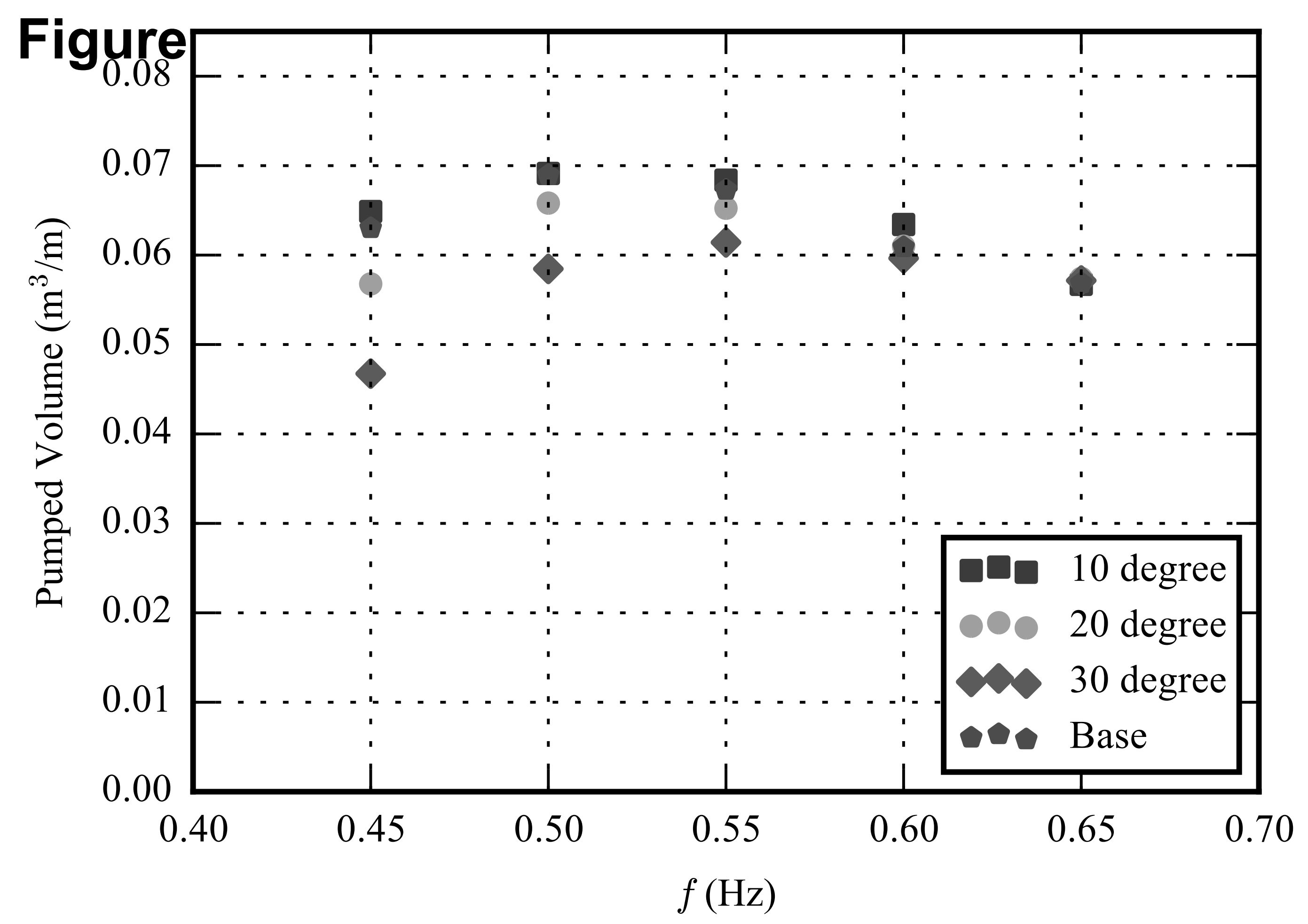



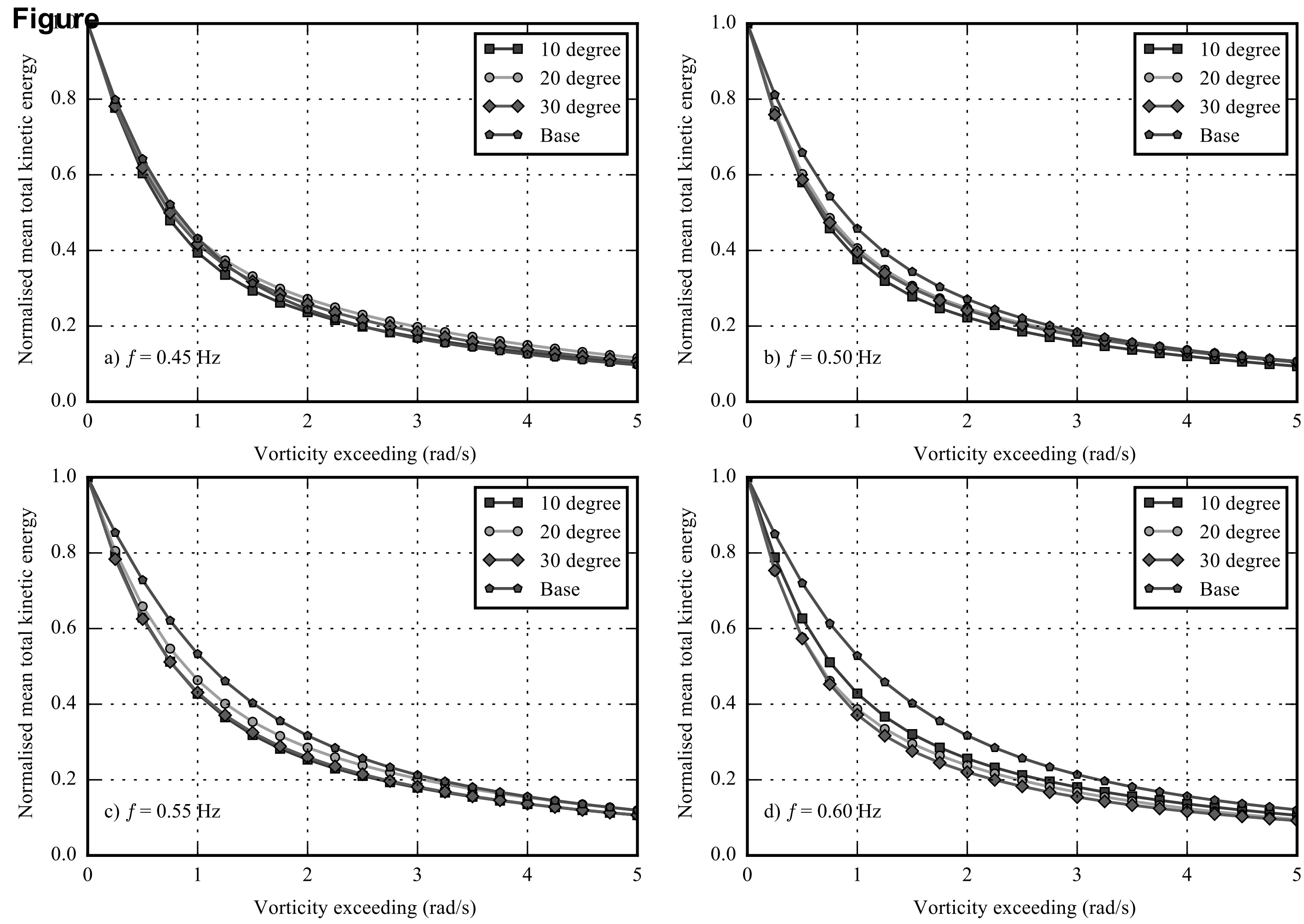

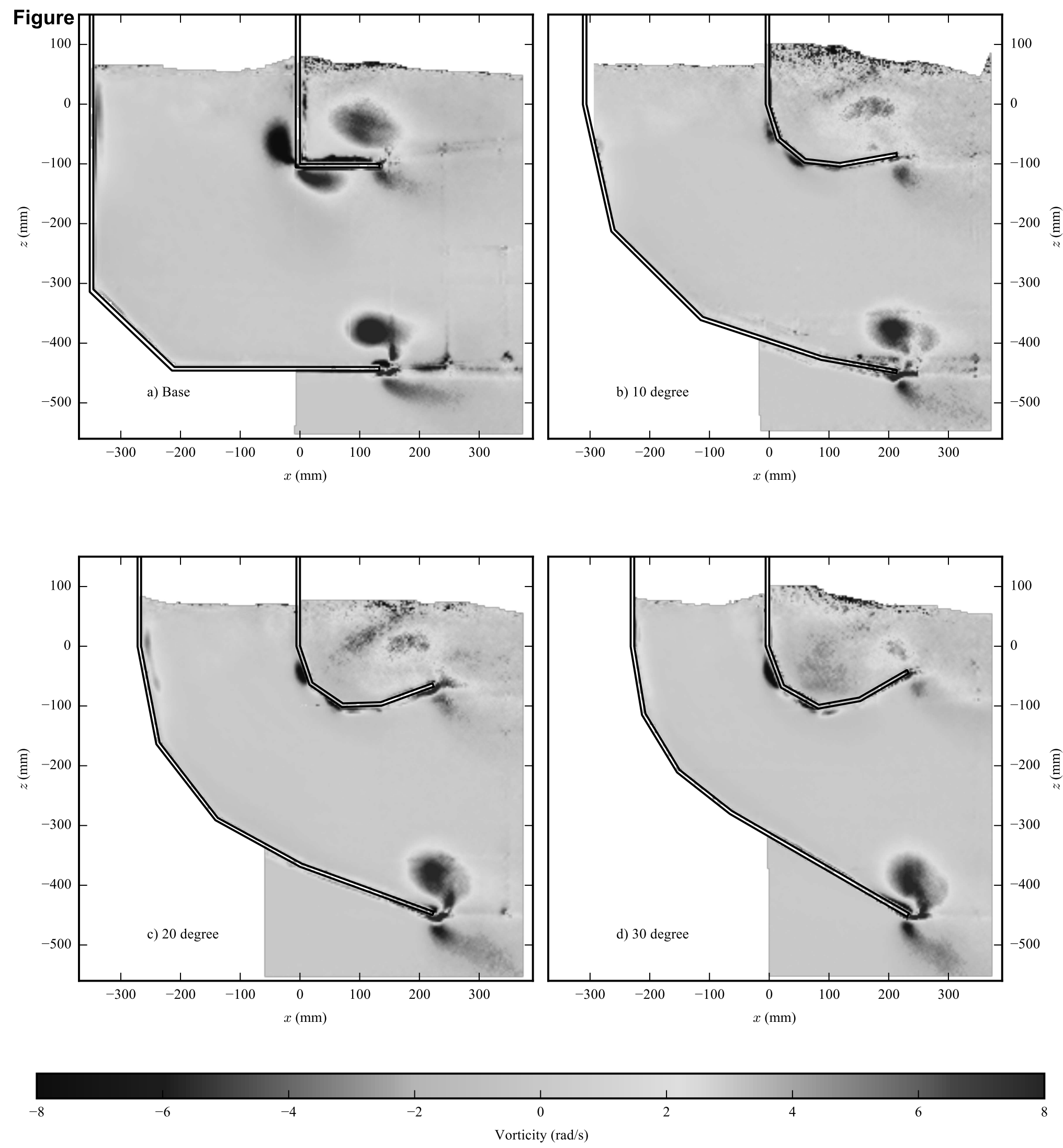

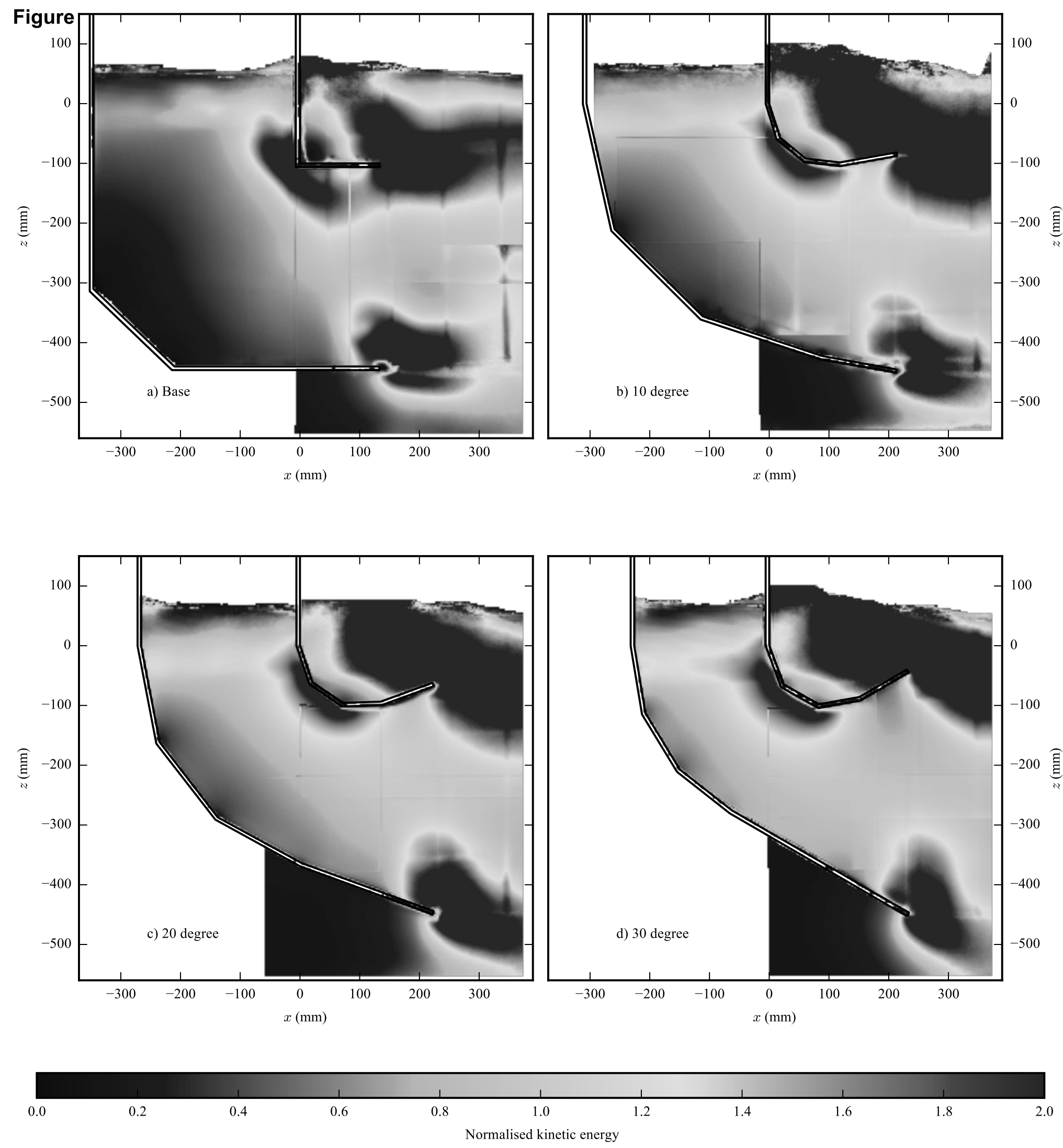

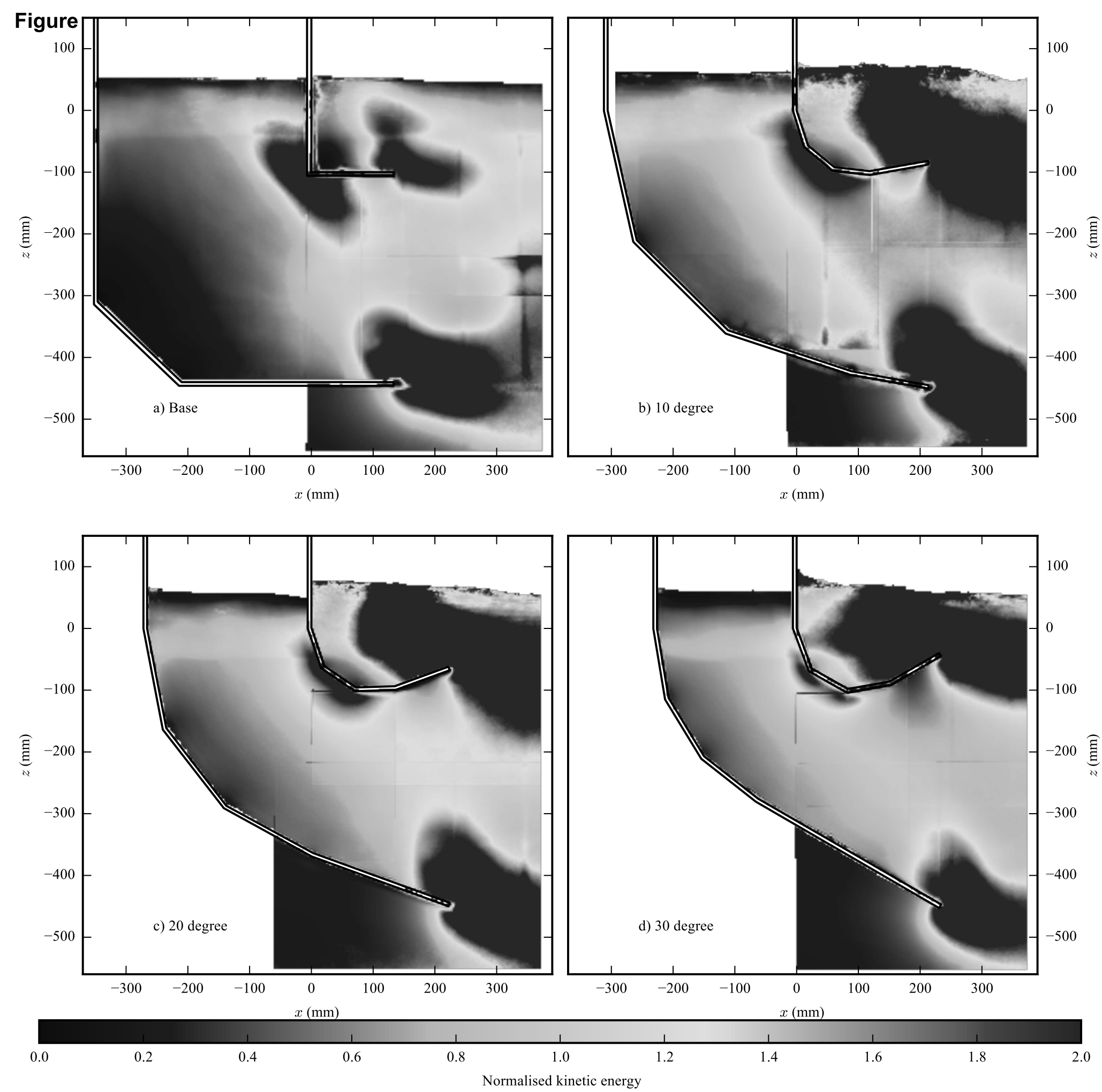

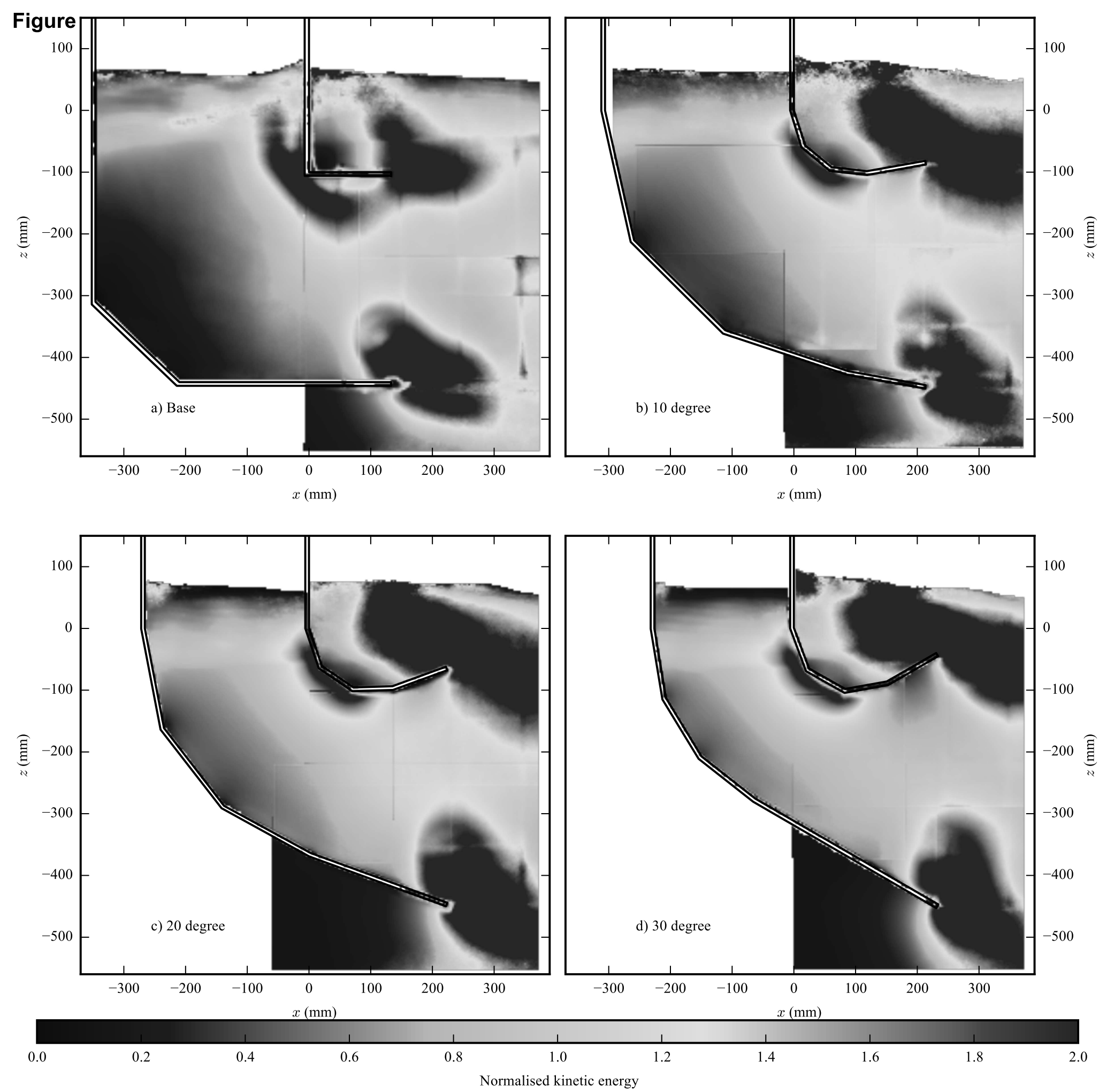

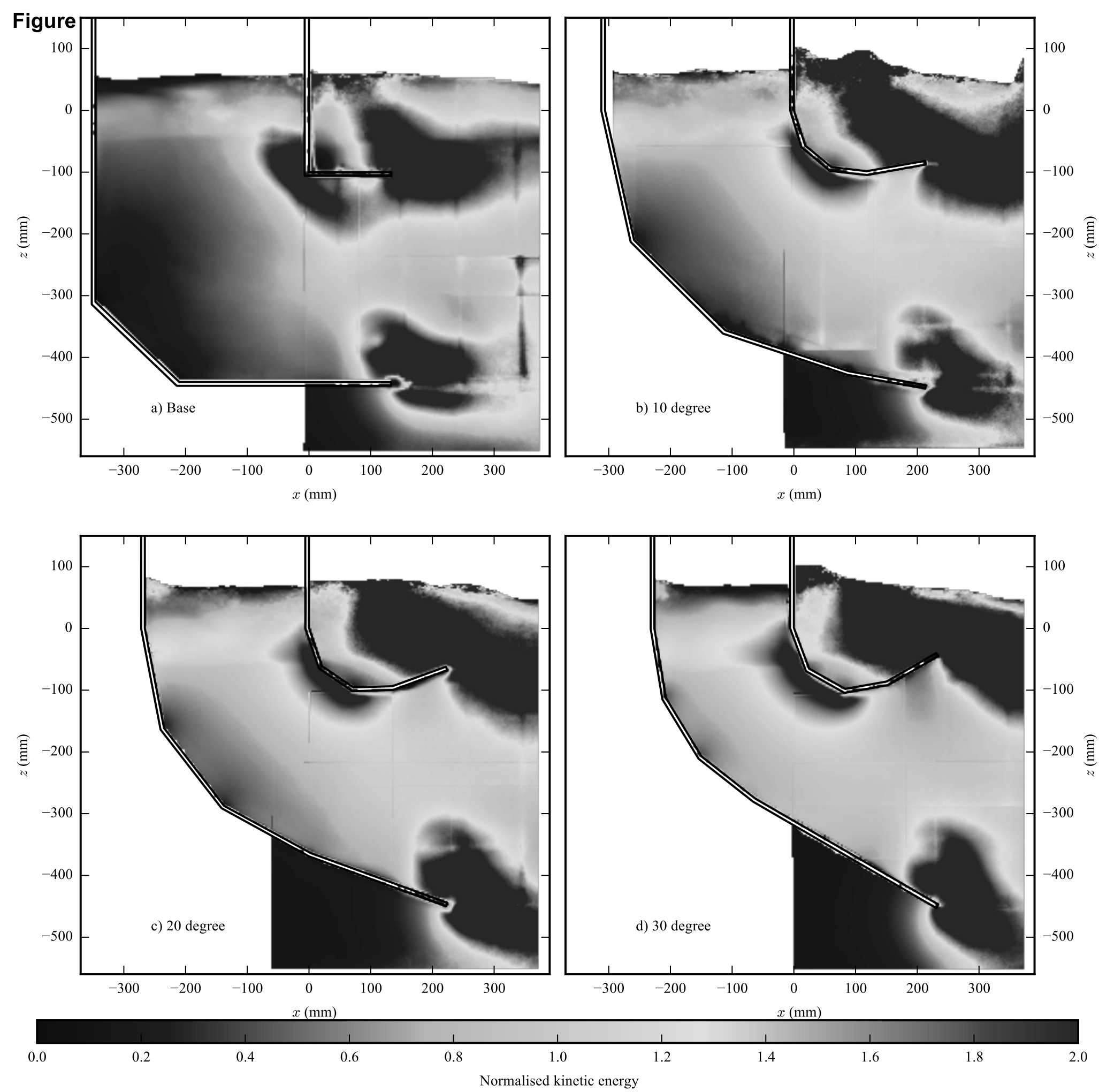

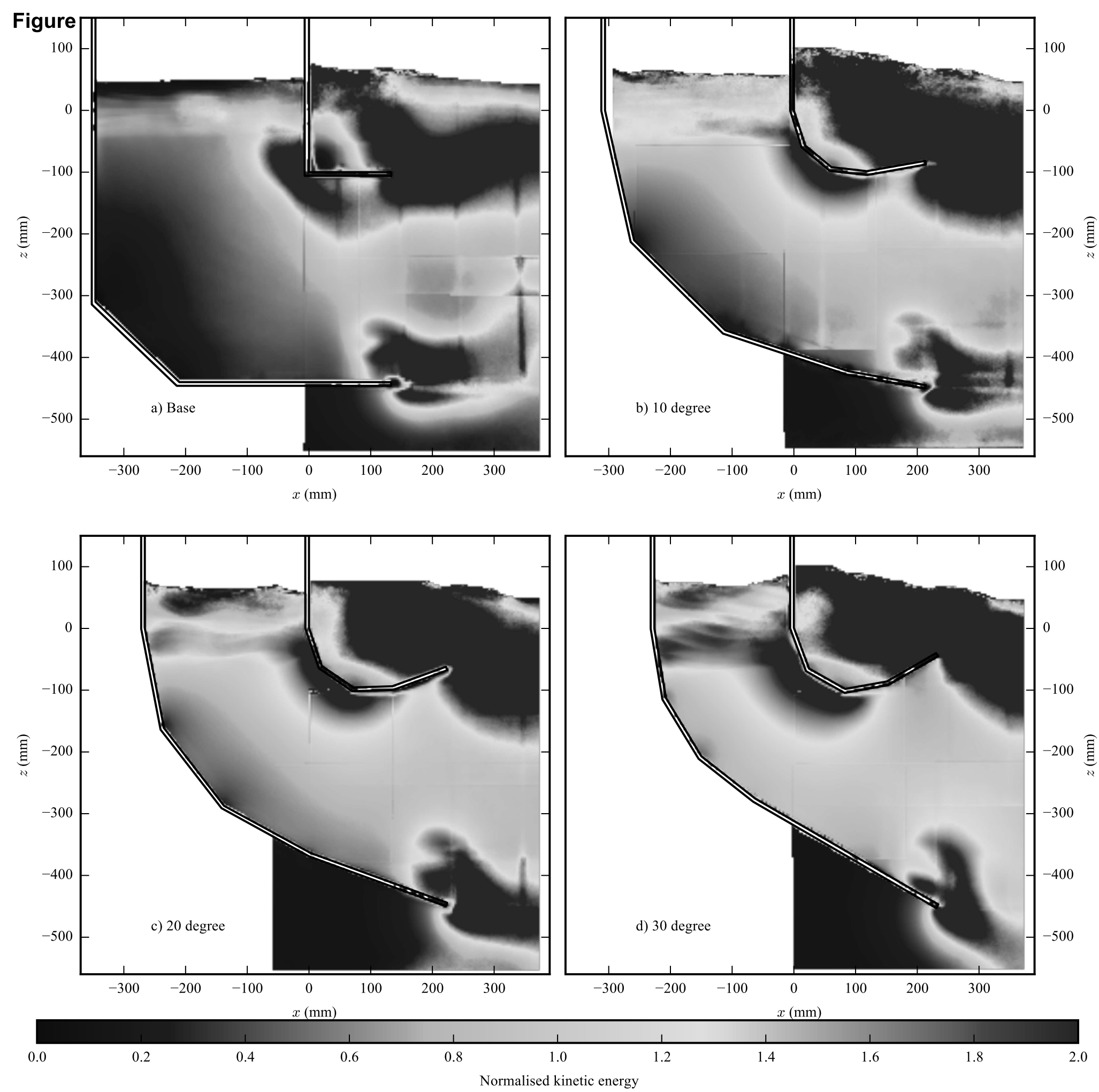

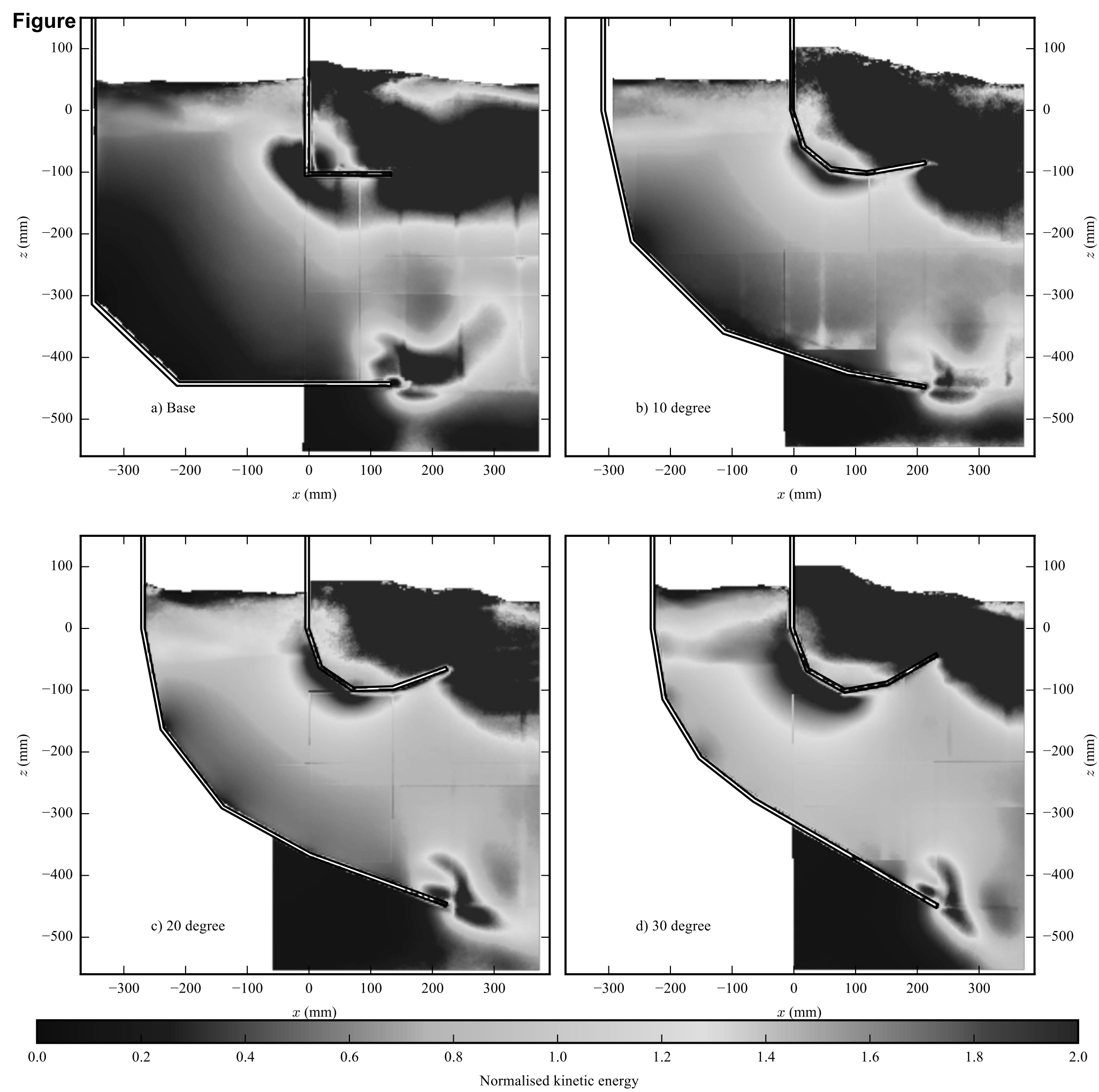
